\title{
PARA AUMENTAR LA COMPETENCIA ENTRE LAS AFP ${ }^{1}$
}

\author{
Salvador Valdés Prieto
}

\begin{abstract}
Este artículo argumenta que entre las AFP no hay competencia en comisiones debido a que el Estado interviene en esta industria de manera asimétrica: niega ayuda institucional efectiva para comparar comisiones de AFP, pero obliga a adquirir el servicio de AFP. Las medidas que el gobierno adoptó en 1997 para que las AFP redujeran sus excesivos costos en vendedores tampoco fueron idóneas. En efecto, ciertas circulares de la Superintendencia permitieron a las AFP acordar un despido paralelo de vendedores y coordinar tácitamente cuotas para el número de vendedores de cada una de las instituciones previsionales. La tolerancia de esta situación generó una suerte de neocorporativismo, contrario al objetivo de evitar que las empresas basen sus utilidades en regulaciones favorables.
\end{abstract}

Salvador Valdés Prieto. Doctor en Economía, MiT. Ingeniero Civil Industrial, Universidad Católica de Chile. Profesor Titular del Instituto de Economía de la Universidad Católica de Chile e investigador del Centro de Estudios Públicos.

${ }^{1}$ Ésta es una versión modificada, en aspectos importantes, del trabajo presentado en un seminario en el CEP el 5 de octubre de 2004 y disponible en www.cepchile.cl ("Ver Noticias Anteriores"). Agradezco las críticas recibidas en esa oportunidad, de Hernán Cheyre y Eduardo Fajnzylber. También agradezco los comentarios de Solange Berstein, Harald Beyer, Jorge Bustos, Rosanna Costa, Alexander Galetovic, Robert Holzmann, Christian Larraín, Guillermo Larraín, Francisco Margozzini, Francisco Mozó, Jorge Tarziján, Rodrigo Vergara, y otros recibidos en seminarios en el Instituto de Economía de la Universidad Católica de Chile y en el CEA de la Universidad de Chile. Ninguno de ellos, por cierto, es responsable de las opiniones expuestas aquí. 
¿Cómo lograr que las AFP efectivamente compitan entre sí en comisiones, en beneficio de los afiliados? Este estudio propone crear un Servicio de Búsqueda de la AFP más barata. Un comité de expertos independientes, elegidos por mérito, licitaría cada tres años las AFP más baratas a nombre de los usuarios de este servicio. No más de dos bloques de 500 mil usuarios podrían ir a una misma AFP. Se presume que el servicio de búsqueda sea solicitado por los afiliados de bajo saldo. Otras dos medidas resultan indispensables para que el Servicio de Búsqueda sea exitoso: (a) exigir a cada AFP actual desdoblarse en una AFP "pura”, cuyas únicas funciones serían la gestión financiera y el contacto con los afiliados, y un "operador básico" que cumpla las demás funciones; y (b) satisfacer la demanda social por comisiones equitativas por medio de una tasa de comisión única aplicada a los cotizantes en todos los “operadores básicos”. Una vez adoptado este paquete de tres medidas, se propone permitir que los bancos creen filiales AFP, siempre que el Banco del Estado quede sujeto a exigencias adicionales.

\section{Introducción}

E ste trabajo analiza el tipo y grado de competencia entre AFP, critica las actuaciones del gobierno en esta materia desde 1997 y propone reformas pro competencia para perfeccionar el sistema previsional. Para mantener esta crítica en perspectiva conviene recordar que muchas otras políticas de pensiones son eficientes en Chile.

En 1980 se reformaron aquellas políticas de pensiones que tenían el objetivo de ayudar a las familias de clase media a vencer su propia imprevisión, por la vía de forzarlas a ahorrar para la vejez. Esa reforma introdujo la capitalización, que es más resistente a las bajas de fertilidad (en reemplazo del reparto), adoptó fórmulas de beneficio actuarial (en vez de por años de servicio), asignó el riesgo agregado mediante reglas y contratos, con contribución definida en la fase activa y beneficio definido en las rentas vitalicias (en vez de una asignación discrecional del riesgo por parte del Congreso), y adoptó la gestión privada de los fondos de pensiones (en reemplazo de la gestión estatal o mixta de las antiguas cajas). Estas reformas fueron muy exitosas. La reforma de 1980 también se hizo en conjunto con una reforma fiscal para aumentar de manera creíble y permanente el ahorro público, lo que contribuyó al rápido crecimiento logrado en 1986-1997 (Corbo y SchmidtHebbel, 2003).

Otras políticas de pensiones ayudan a las familias de clase media alta a vencer su propia imprevisión por medio de incentivos, fiscales y regulato- 
rios, al ahorro para la vejez. Aquí el éxito corresponde al APV (Ahorro Previsional Voluntario) adoptado en 2002, pues el intento contenido en la reforma de 1980 no logró una cobertura razonable.

Las políticas que eximen a los trabajadores por cuenta propia de la obligación de cotizar interactúan con la pensión mínima (creada en 1952) y la pensión asistencial (creada en 1975) para canalizar subsidios significativos a los ancianos pobres. Sin embargo, ello ha incentivado también la informalidad laboral. Esta combinación de políticas ha creado cierta confusión ${ }^{2}$.

Dentro de este panorama, siempre fue preocupante la falta de competencia en comisiones entre AFP. En 1981-1982 y de nuevo en 1993-1997 esta situación inducía a las AFP a gastar en vendedores mucho más de lo esperado por quienes diseñaron el sistema. Para reducir el gasto en honorarios de vendedores, las autoridades recurrieron en 1997 a medios que hoy lamentan. La Superintendencia de AFP, por medio de circulares, permitió a las AFP acordar un despido paralelo de vendedores y coordinar tácitamente cuotas para el número de vendedores de cada AFP, en una alianza donde la autoridad inicialmente tuvo buenas intenciones. La adopción en 1997 de este "neocorporativismo" es grave, pues permitiría que eventuales futuras autoridades irresponsables se alíen con las grandes AFP con intenciones distintas. En efecto, desde 1998 la autoridad quedó en condiciones de tomar medidas administrativas que reducirían muy significativamente las utilidades de las AFP, situación que se mantiene, aunque en menor grado, desde noviembre de 2001. A partir de 1998, las AFP cobran a cada uno de los trabajadores comisiones que exceden en mucho el costo económico del servicio prestado, y debido a que esas circulares también bloquearon la entrada de nuevas AFP, durante los últimos seis años han logrado una utilidad sobrenormal ${ }^{3}$ anual de 80 millones de dólares.

Éste no es un caso cualquiera de competencia insuficiente, como los que analiza el Tribunal de la Competencia todos los años, por dos razones: el neocorporativismo deja a las utilidades de las AFP expuestas a medidas

${ }^{2}$ Como la ley obliga a cotizar a apenas un 30\% de la población mayor de 15 años, el grueso de los afiliados pasa la mayor parte del tiempo sin cotizar. Esto incluye ocupados por cuenta propia, dueñas de casa, inactivos y desempleados. Según una declaración de Michelle Bachelet en Nueva York, el sistema previsional “está en crisis” porque cerca de la mitad de los afiliados recibirá pensiones inferiores a la mínima (ver El Mercurio de Santiago, 14 de enero 2005, p. B2). Sin embargo, la gran mayoría de los afiliados que tendrá una pensión baja no es pobre, según demuestra la encuesta CASEN. El propio Mideplan informa en su página web que en 2000 sólo el $7 \%$ de los ancianos chilenos estaba debajo de la línea de la pobreza.

${ }^{3}$ Esto significa que la utilidad excede a aquella necesaria parar atraer el capital que está utilizando la firma, ajustando por el nivel de riesgo del negocio. 
administrativas, incluyendo circulares de la Superintendencia, en un contexto en que las AFP toman decisiones de impacto macroeconómico. Si en el futuro las AFP resistieran eventuales solicitudes de favores de parte de autoridades irresponsables, por ejemplo referidos a votación en las $\mathrm{OPA}^{4}$, a votación por directores en empresas, o incluso a adquisición de títulos de empresas estatales o del fisco, las AFP podrían perder esta utilidad sobrenormal. El gran tamaño de los fondos de pensiones y la alta concentración de su gestión financiera podría hacer que esos favores dañen la asignación del ahorro nacional, empeoren la gestión de las empresas cuyos controladores son elegidos en parte por las AFP, e impidan operar correctamente al mercado del control corporativo.

Este trabajo propone una solución que busca los siguientes tres beneficios:

(a) Generar una alternativa de mercado al neocorporativismo y a la colusión comercial, cuyos costos potenciales para el país son enormes. Se trata de impedir que las utilidades de quienes gestionen los fondos de pensiones dependan de intercambios de favores con la autoridad;

(b) Bajar comisiones mediante una disminución del gasto en vendedores, y eliminar barreras económicas y regulatorias a la entrada de la actividad de AFP, y

(c) Desconcentrar la gestión financiera de los fondos de pensiones, de manera que el costo de capital de las empresas no pueda ser controlado por ningún actor específico, sea AFP o banco.

Las secciones que siguen muestran que lograr esas metas exige cumplir tres objetivos:

(a) Reducir las economías de escala de las empresas que hacen la gestión financiera.

(b) Eliminar la asimetría entre la obligación legal de comprar servicios a alguna AFP y la ausencia de ayuda institucional efectiva para comparar comisiones de AFP.

(c) Satisfacer la demanda social por comisiones equitativas por medios más eficientes que la actual imposición de que cada AFP por separado aplique una tasa de comisión única al salario.

Se proponen tres medidas, en un paquete cuyo éxito depende de una aplicación conjunta:

(a) Exigir a cada AFP actual desdoblarse en una AFP "pura", cuyas únicas funciones serían la gestión financiera y el contacto con los afiliados, y un “operador básico” que cumpliría las demás funciones.

${ }^{4}$ OPA es Oferta Pública de Acciones. 
(b) Crear un canal institucional nuevo para que las AFP “puras” capten afiliados, que cubra a un número sustancial pero nunca a todos los afiliados. Este nuevo canal sería un Servicio de Búsqueda de la AFP más barata, creado expresamente. La propuesta se traduciría en que los afiliados que reciban el servicio de búsqueda sumen en conjunto menos del 38\% de los fondos de pensiones.

(c) Satisfacer la demanda social por comisiones equitativas mediante una única tasa de comisión aplicada a los clientes de todos los "operadores básicos”. Respecto a las AFP “puras”, esa demanda se satisfaría sólo para los afiliados que usen el servicio de búsqueda de la AFP más barata.

Las secciones 2 a 5 presentan datos, antecedentes y el diagnóstico. La sección 6 presenta los detalles de la propuesta respecto al paquete unitario, en sus tres componentes. La sección 7 resume las consecuencias para los afiliados.

Conviene mencionar que, aunque permitir que los bancos creen filiales AFP es equitativo, su entrada no elevará la sensibilidad de los afiliados a las diferencias de comisión. Este hecho impide a los bancos competir con comisiones, forzando en vez una competencia con vendedores y ventas cruzadas, tal como ocurrió hasta 1997. La entrada de los bancos repite el escenario de rivalidad comercial que llevó al neocorporativismo. Habrá, sin embargo, una diferencia: el Banco del Estado creará una filial AFP. Su prestigio en amplios sectores y su potente red comercial permitirían a una AFP Banco del Estado tener una alta participación de mercado. Si las decisiones financieras de una AFP Banco del Estado llegaran a ser determinantes para las demás AFP, un eventual gobierno irresponsable, que controlaría Banco del Estado, gozaría de un instrumento para determinar la asignación de cartera de las AFP, influyendo inapropiadamente sobre el costo de fondos a largo plazo de las empresas y sobre el éxito de cualquier OPA. Así, la mera entrada de bancos podría empeorar la situación.

En cambio, una reforma en la dirección propuesta perfeccionaría la competencia y dispersaría la gestión de los fondos de pensiones, consolidando al sistema previsional. En ese escenario, la entrada de los bancos sería un aporte bienvenido.

Si se adopta el paquete propuesto, las siguientes medidas también serían deseables, sin ser esenciales:

(a) Permitir a los bancos crear filiales AFP, si al mismo tiempo la ley impone al Banco del Estado salvaguardias creíbles contra la politización de una eventual filial AFP. Las decisiones por proteger son las de inversión, votación en las OPA y votación para elegir directores en otras empresas. 
(b) Permitir a aquellos empleadores que cumplan requisitos de gobernanza eficiente, prestar a sus empleados un servicio de búsqueda de la AFP más barata.

(c) Permitir a las AFP "puras" pagar premios al contado a cambio de convenios de permanencia con afiliados que contacten en forma individual, dentro de ciertos márgenes.

En este trabajo no nos extendemos respecto a las medidas (b) y (c), recién mencionadas, por falta de espacio.

\section{Demanda y oferta de información sobre comisiones de AFP}

Esta sección evalúa empíricamente la hipótesis de que la información de la cartola cuatrimestral bastaría para que suficientes afiliados comparen precios entre AFP, permitiéndoles elegir con eficiencia.

\subsection{La evidencia sobre la sensibilidad de la demanda a las comisiones}

Los precios de una AFP son las comisiones regulares, como la porcentual y la fija. El grado de competencia en precios entre AFP se mide a través de la "elasticidad" de la demanda individual de una AFP frente a cambios en el precio ${ }^{5}$. Cuando esta elasticidad es menor que 1,0 la AFP no enfrenta competencia en precios suficiente como para inducirla a limitar sus precios $^{6}$. Para medir esta elasticidad se necesitan estudios econométricos que controlen por cambios simultáneos en los demás factores que afectan a la demanda. Estos otros factores son el número de vendedores, el gasto en publicidad, las diferencias de retorno del fondo de pensiones en los últimos períodos (éste es el único indicador de la calidad de la gestión financiera disponible para los afiliados), regalos de servicios y dinero, y otros.

${ }^{5}$ Otras medidas diferentes de la elasticidad no son válidas. Por ejemplo, según la encuesta HLSS, hasta 2002 el 64\% de las afiliadas mujeres y el 54\% de los hombres chilenos jamás se habían cambiado de AFP. En teoría, esa baja rotación es compatible con una alta elasticidad precio, es decir con cero cautividad de las clientelas. En efecto, si las diferencias de comisión entre AFP tuvieran una magnitud fija, no habría razones para esperar que alguien se cambie. Una baja rotación también es compatible con una baja elasticidad precio. Lo que importa para la competencia es la elasticidad precio.

${ }^{6}$ Cuando la elasticidad precio es menor que $1 \mathrm{y}$ el costo marginal es positivo, las utilidades de la empresa aumentan cuando eleva el precio. En efecto, la reducción de utilidad asociada a perder unos pocos clientes es menor que el incremento de utilidad asociado a aumentar el margen sobre los clientes que permanecen con ella. 
Los estudios econométricos ${ }^{7}$ muestran que la elasticidad de los traspasos a la diferencia de comisiones porcentuales, a nivel de cada AFP individual, en el período 1992-1997, fue menor que 1,0 , aunque superior a cero. Según el estudio más completo de los mencionados en la nota 7 , esta elasticidad fue menor que 1,0 con una probabilidad de 76\%, en ese período, para el panel de todas las AFP que representa el comportamiento de los cotizantes de ingreso mediano. Al mismo tiempo, y sin contradecir lo anterior, esta elasticidad precio fue 2,4 para una AFP mediana cuyos cotizantes tenían ingresos superiores al promedio. Esta última elasticidad todavía implica un margen óptimo de $71 \%$ sobre el costo marginal.

Esa elasticidad baja hasta ser indistinguible de cero en el período 1998-2002. Esto indica que el despido masivo de vendedores redujo la elasticidad precio. Se deduce que los vendedores informaban las comisiones a los afiliados y que contribuían a que hubiera más competencia en precios. La elasticidad para la diferencia de comisión fija es menor que 1,0 con un 95\% de confianza, en todos los períodos y en casi todos los estudios. Estos estudios confirman la opinión de ejecutivos de la industria de AFP, reconocida en declaraciones a la prensa en diversas ocasiones.

En forma independiente, la encuesta Historia Laboral y Seguridad Social, realizada en 2002, revela que el 95\% de los afiliados desconoce las comisiones que paga a su propia AFP, y que sólo el 1\% de los afiliados utiliza la cartola, a pesar de que desde 1993 ese documento muestra el monto de la comisión pagada (Larraín, 2004, pp. 10 y 13). Esto ocurría a 21 años de la creación del sistema de AFP.

Estos datos implican que aunque la ley sea clara en dar libertad de cambiarse de AFP, cada AFP establecida tiene una "clientela cautiva de hecho”, definida como una situación en que la elasticidad precio es menor que 1,0. Ello implica que las distintas AFP están en mercados separados, donde cada una tiene un monopolio. Esta situación implica que una hipotética colusión en precios entre AFP no generaría ventajas económicas adicionales a cada AFP participante, porque cada una puede obtener esas ventajas elevando el precio por sí sola. Esto nunca fue deseado por los creadores del sistema de AFP.

Afirmamos que estos hechos son compatibles con la racionalidad de los trabajadores. Es racional no utilizar información sobre comisiones (dis-

7 Ver Marinovic (2000), Berstein y Micco (2002), Valdés y Marinovic (2003, Cuadros VII.3 y VII.4), y el trabajo más robusto de Marinovic y Valdés (2005). Estos dos últimos distinguen entre la elasticidad precio de los traspasos (flujos) y la elasticidad precio del stock de cotizantes. Por su naturaleza el stock es menos sensible que el flujo a las diferencias de comisión. La elasticidad que considera una AFP que desea maximizar el valor presente de sus flujos de caja es la del stock de cotizantes (ver una demostración matemática en Valdés 2002). Estos dos últimos trabajos también consideran rezagos de la variable dependiente. 
ponible en periódicos, cartolas e internet) cuando el costo de conceptualizar esas comisiones es alto. Creemos probable que este costo sea alto para los afiliados chilenos porque la gran mayoría jamás ha tenido un fondo mutuo y para muchos resulta complejo calcular un porcentaje. También es racional no utilizar la información cuando el costo de cambiarse es alto: visitar una agencia de AFP en horario de trabajo es costoso y el costo de cambio aumenta cuando se le exige guardar una cartola (Klemperer, 1995). También es racional no informarse cuando se estima que es bajo el valor de la diferencia de comisión multiplicada por un sueldo bajo y por una densidad baja. Además, es racional postergar la inversión en informarse cuando el costo de dejarla para el mes siguiente es pequeño y el beneficio percibido de postergarla es alto. Por último, si se cree que la tasa de comisión es un impuesto, porque el Estado prohíbe dejar de comprar, no hay nada que investigar.

La hipótesis de racionalidad predice que los afiliados reaccionarían si una AFP alejara su comisión respecto de las demás en cantidad suficiente para cubrir el costo de informarse. También predice que si cada AFP eligiera su nivel de comisión sujetándose a la condición de que no sea muy diferente de otras, entonces un afiliado individual no ganaría informándose, aunque el nivel absoluto de todas las comisiones fuese alto. En estas condiciones, si no fuera posible competir con vendedores ni regalos ni fuera posible entrar, el equilibrio de mercado sería con todos los precios muy por sobre el costo medio económico y con muchos cotizantes a punto de optar por ocupaciones independientes, que están libres de la obligación de pagar comisión (Salop y Stiglitz 1977, Stiglitz 1989).

Sin embargo, la presencia de altos márgenes incentiva a otros a proveer la información que no buscan los afiliados por sí mismos. A continuación consideramos los topes a las comisiones creados por la aparición de otros proveedores de información.

\subsection{El costo de contacto de los contratos individuales}

Una AFP podría crecer elevando la sensibilidad a las comisiones con algún sistema apropiado, por ejemplo sumando las comisiones en el tiempo por la vía de cobrarlas sólo una vez al año. Para lograr el máximo efecto habría que eludir la actual prohibición legal de que una AFP adopte el siguiente plan de precios: un descuento en pesos al contado, a cambio de un compromiso razonable de permanencia (con una multa por incumplimiento y un plazo de compromiso acotados por ley). Ese descuento concentraría en un solo pago las diferencias de comisión de toda la permanencia compro- 
metida, superando en magnitud a una diferencia que considere sólo unos pocos meses y que lleve a postergar la decisión de informarse. Además, este plan de precios ofrecería un pago justo cuando el afiliado compare los beneficios de informarse de los precios con los costos de hacerlo, que es el momento de máxima notoriedad.

Este plan de precios es tan obvio, que fue inventado ya en 1981. Las AFP superaron la prohibición citada con un sustituto: contratar vendedores remunerados sólo contra el éxito en el traspaso. El vendedor a su vez aprovechaba que su gran número y su informalidad impedía a la Superintendencia de AFP fiscalizar la prohibición de pagar descuentos o dar servicios extra en forma efectiva. Los vendedores otorgaron directamente el descuento, con cargo a sus propios honorarios. El descuento tomó la forma de dinero, regalos y servicios varios.

Sin embargo, este plan de precios sufre del alto costo de los contactos individuales ${ }^{8}$. Considerando la evidencia empírica en cuanto a que el vendedor promedio logra menos de 10 traspasos al mes, y que el sueldo del vendedor es por lo menos igual al salario imponible medio (sin considerar costos de supervisión y entrenamiento), que en Chile es de 500 dólares al mes (Ch. \$300.000), resulta que el costo por contacto exitoso es al menos 50 dólares. Considerando una permanencia de 36 meses, un premio o “descuento de entrada” de 17 dólares (Ch. \$10.000) y una tasa de costo de fondos para la AFP de 15\% real anual, se requiere de un margen entre la comisión regular y el costo marginal de 2,26 dólares (Ch. \$1.360) al mes (en promedio) para financiar el costo de contacto y el premio. Para un afiliado que declara el salario mediano de 333 dólares al mes (Ch. \$200.000) y tiene una densidad de cotización de 70\%, este margen equivale a 1,00\% del salario. Esta enorme cifra es un tercio de la tasa de comisión observada a mediados de los años 90. Coincide con el hecho de que el gasto en honorarios de vendedores llegó a representar casi un tercio de los ingresos por comisiones de las AFP.

La conclusión es clara: un plan de precios como el propuesto no permite elevar la sensibilidad a los precios de los afiliados de salario medio, a menos que se eleven las comisiones pagadas en $1,00 \%$ de los salarios. Viceversa, si el nivel de las comisiones es tan alto como para financiar el costo de contacto individual, entonces la irrupción de vendedores impedirá que la comisión neta de regalos continúe subiendo, porque los propios vendedores entregarán información sobre las comisiones que elevan la elasticidad precio de la demanda percibida por cada AFP.

${ }^{8}$ La presencia de este costo de contacto está confirmada por los estudios econométricos. En ellos, la variable significativa para explicar los traspasos es la interacción entre el número de vendedores y el descuento estimado por cada traspaso. Es decir, sin vendedores no hay sensibilidad al descuento, y éste pierde toda efectividad. 
Para un afiliado de altos ingresos, el costo relativo de contacto es menor porque el vendedor gana menos que él. En efecto, un cálculo análogo para un afiliado con el máximo salario imponible, que en Chile es 1.720 dólares al mes (60 UF al mes) y densidad 100\%, a quien se le ofrezca un premio (proporcional al salario) de 170 dólares, muestra que el costo de contacto se financia con un margen de sólo 0,26\% del salario. Sin embargo, cuando la ley prohíbe el compromiso de permanencia, como ocurre en Chile, hay un obstáculo: la competencia entre vendedores induce a los afiliados de mayor ingreso a reducir su permanencia para acceder al descuento con más frecuencia. Siguiendo el ejemplo, este proceso elevaría la rotación de esos afiliados hasta que la permanencia media sea 9 meses (= 36 meses $\mathrm{x}$ $0,26 / 1,00)^{9}$.

Este proceso no opera respecto de los afiliados de alto ingreso que son fieles a una AFP por otras razones, distintas de las comisiones. Respecto de ellos, la competencia en precios aumentaría si la ley permitiera a las AFP ofrecer directamente los planes de precio propuestos, porque tendrían menos costo que un descuento indirecto vía vendedor. Si bien esa eventual liberalización de planes de precio pondría un techo más bajo a las comisiones de estos afiliados, beneficiaría sólo a unos pocos cientos de miles de afiliados de mayor ingreso. Su comisión quedaría muy por debajo de aquella pagada por los cotizantes de ingresos medios y bajos, cuando ambas se expresan como porcentaje del salario. Además, las comisiones pagadas por los afiliados de ingresos medios seguirían financiando un costo de contacto enorme, cercano a 1,00\% del salario.

Los vendedores desempeñan otras funciones, que son valiosas. Ellos reducen el costo de cambio de AFP que paga el afiliado. También informan al afiliado sobre las comisiones y otros atributos. Por último, educan al afiliado en materias financieras, lo cual es muy determinante en el largo plazo. Por estas razones, sería incorrecto sostener que en una industria con demanda obligada como la de AFP, toda inversión comercial es socialmente ineficiente. Sin embargo, cuando la función principal del vendedor es canalizar descuentos, es probable que el número de vendedores sea socialmente excesivo.

9 ¿Puede una AFP evitar este resultado remunerando a su fuerza de ventas por la “mantención” del afiliado, en vez de por el éxito en atraerlo? Por ejemplo, el honorario del vendedor podría pagarse en cuotas mensuales, cada una condicionada a que el afiliado haya cotizado el mes anterior, con lo cual se incentivaría al vendedor a preferir afiliados fieles. Esta salida sirve sólo si el afiliado es fiel. Sin embargo, este esquema genera un incentivo a los afiliados para no ser fieles. Además, el vendedor mantenedor tiene baja efectividad ante vendedores de otras AFP remunerados por el mero traspaso, sin condiciones. Por eso, el vendedor mantenedor ve que sus honorarios son destruidos por las acciones de los vendedores remunerados por traspaso. La remuneración por mantención no es creíble para el vendedor. 


\subsection{Contacto por otros canales de distribución}

Otra forma de reducir el costo de contacto es aumentar el número de traspasos exitosos al mes por vendedor. Estos supervendedores serían "brokers" especializados. Sin embargo, el afiliado tendría que informarse respecto a las comisiones de los brokers y compararlas, lo cual es muy improbable dada la evidencia ya citada. Esto haría que las comisiones de los brokers alcanzaran niveles enormes.

Es más prometedor considerar canales de distribución distintos de los vendedores de AFP. Un banco comercial y una aseguradora pueden actuar como canal de distribución. El cliente elige banco por un conjunto de servicios asumiendo un costo de contacto que es común a todos ellos, de forma que el costo de contacto asignable al servicio de AFP podría ser bajo. Sin embargo, como prueba la experiencia de Australia, los bancos que venden paquetes de servicios logran costos de cambiarse de banco muy elevados, lo que a su vez permite cobrar comisiones muy altas. Los bancos siguen haciendo un contacto individual, que tiene alto costo. Además, los bancos y aseguradoras no sirven a los afiliados de ingresos bajos. En Chile la cobertura de la cuenta corriente bancaria se limita al segmento $\mathrm{ABC} 1^{10}$.

Si el afiliado es insensible a la comisión del banco en el servicio de AFP, entonces es rentable para el banco atraerlo con una "venta cruzada": otorgarle un subsidio en algún otro bien que el afiliado sí valora, a cambio de que acepte el servicio de AFP a un precio enorme. En los bancos esta "venta cruzada" puede tomar la forma de concederle un mayor cupo de crédito de consumo, a cambio de sobrecomisiones en el servicio de AFP. Esto es un problema cuando el afiliado no se da cuenta de que el estímulo ofrecido por el banco es a cambio de una sobrecomisión en el servicio de AFP, al cual él no es sensible por culpa del contexto institucional.

Las asociaciones de empleadores y los sindicatos pueden lograr costos marginales de contacto mucho menores que los bancos, porque el contacto es colectivo. Para el afiliado, esto implica empaquetar la elección de AFP con la elección de empleador o la afiliación a un sindicato. En ciertos países —Dinamarca, Holanda, Australia — las asociaciones de empleadores, en conjunto con los sindicatos sectoriales, comparan precios de servicios de AFP por la vía de licitaciones, logrando una alta elasticidad respecto al precio y bajas comisiones. Esto también ocurre en América Latina, pues en 1999 el gobierno de Panamá representó a sus empleados licitan-

${ }^{10}$ Las AFP que hace algunos años pertenecen a conglomerados bancarios de matriz extranjera no han dado señal alguna de bajar su costo de contacto con los millones de afiliados que no pertenecen al segmento ABC1. 
do el servicio para un sistema de ahorro voluntario similar al APV y logró bajas comisiones.

Sin embargo, estos canales de distribución también sufren conflictos de interés, que deben ser limitados: ¿qué incentivo tiene el empleador o el sindicato para servir bien a los afiliados que representa, cuando ellos no pueden vigilarlo por estar desinformados? Considérese un empleador o directiva sindical libre de una vigilancia efectiva. Podría "vender" el paquete de afiliados que le confiaron la elección de AFP a aquella AFP que le ofrezca (a través de terceros, y en forma secreta) el mayor premio, que a su vez puede consistir en acceso a servicios escasos u otro bien difícil de observar. La AFP recomendada podría ser la que cobre la peor comisión a los afiliados (y entregue el peor servicio).

Estos conflictos de interés pueden ser secundarios si el empleador o el sindicato queda sujeto a una estructura de gobernanza efectiva, como comités de vigilancia, elecciones en el sindicato y auditorías externas. Los afiliados podrían usar esas estructuras para monitorear el desempeño del empleador o del sindicato y castigarlo. Una ventaja de los empleadores y sindicatos sobre los bancos es que algunos de aquéllos ya cuentan con estas estructuras de gobernanza. En suma, el contacto por estos medios colectivos puede ser una herramienta eficiente para crear una ayuda institucional para comparar precios, si las políticas públicas exigen la presencia de estructuras de gobernanza que impidan abusos.

Sin embargo, este requisito no se cumple para la pequeña y microempresa. Estimamos que en Chile el $67 \%$ de quienes están obligados a cotizar labora en organizaciones con menos de 200 empleados $^{11}$. El 33\% restante es una cifra importante, lo cual implica que el contacto por medios colectivos puede ser un valioso complemento a otras políticas. Sin embargo, ésta no puede ser la política principal, porque su cobertura es insuficiente. También debe recordarse que, en promedio, los trabajadores de organizaciones con 200 o más empleados son los de mayores ingresos, lo que implica que una autorización simple de descuentos en las comisiones de AFP a grupos contactados por medios colectivos sería regresiva.

${ }^{11}$ Fuente: La encuesta Casen 2000 entrega la distribución de los ocupados según rangos de tamaño del empleador y la encuesta INE de Sept.-Nov. de 1993 reporta que el 28,8\% del empleo es para trabajadores por cuenta propia y familiares no remunerados, que laboran en organizaciones de 1 a 9 trabajadores y no están obligados a cotizar. Combinando ambas fuentes se deduce que, de los obligados a cotizar, el $67 \%$ labora en organizaciones con menos de 200 empleados (el 26,7\% está en organizaciones de 1 a 9 trabajadores, otro $23,0 \%$ en organizaciones con 10 a 49 trabajadores, y otro $17,3 \%$ en organizaciones de 50 a 199 empleados). 


\subsection{El Servicio de Búsqueda propuesto}

El grueso de los afiliados no considera las comisiones al elegir AFP, y eso genera incentivos para que las AFP suban las comisiones. Los altos márgenes incentivan la inversión comercial excesiva cuando hay competencia entre AFP. Sólo una comisión suficientemente alta —más que la actual- incentivaría la aparición de otros canales de información.

Algunos analistas han puesto su esperanza en que el costo de contacto individual bajaría si una fracción grande de los siete millones de afiliados chilenos tuviera acceso a internet. Sin embargo, en 2003 sólo había 500.000 usuarios de internet (24\% de la población activa), con sólo $40 \%$ de las conexiones en banda ancha ${ }^{12}$. La evidencia de la telefonía celular es contundente: la tasa de penetración de los celulares de prepago fue sólo $50 \%$ en los estratos C2, C3 y D en $2003^{13}$. Y los segmentos donde sí ha penetrado internet no han aumentado su sensibilidad a las diferencias de comisiones de AFP. No hay evidencia que justifique confiar en que internet solucionará estos problemas.

Sostenemos que hay una falencia — no planeada - en el diseño original de la reforma de 1980: existe una asimetría entre la obligación legal de comprar servicios a alguna AFP y la ausencia de ayuda institucional efectiva para comparar comisiones de $\mathrm{AFP}^{14}$. Cuando el Estado chileno ha obligado a comprar otros servicios a la gran masa de trabajadores, no ha obligado al individuo a comparar precios por su cuenta. Un ejemplo es la selección de la mutual que cubre los accidentes del trabajo (el Comité Paritario en la empresa elige, y si no lo hace, la ley designa a un proveedor residual, que es el INP). Otro ejemplo es el seguro de cesantía creado en 2001, para el cual el Estado organizó una licitación con el fin de elegir al proveedor de mínimo precio. En la educación obligatoria, el financiamiento compartido es opcional y es pagado por los padres de su propio bolsillo, no de un descuento por planilla, y esto fuerza a los padres a tener experiencia personal e inmediata de los precios.

Nuestra solución es terminar con esta asimetría, creando ayuda institucional efectiva para comparar comisiones de AFP. La propuesta tiene cuatro componentes:

${ }^{12}$ Fuente: Agenda Digital, informe Masificación del Acceso. Se espera una conectividad de $10 \%$ de los hogares para 2006.

${ }^{13}$ Fuente: Revista Qué Pasa, 5 de diciembre de 2003, Santiago.

14 Desde 1993 la cartola incluye información de comisiones, con un indicador llamado "rentabilidad de la cuenta", que es una rentabilidad neta de comisiones. Sin embargo, las encuestas y la econometría demuestran que este indicador no fue ni es utilizado por los afiliados para comparar precios. 
1. Se presumiría por ley que todos los afiliados cuyo saldo en la cuenta individual fuese inferior a cierto umbral, solicitan un Servicio de Búsqueda de la AFP más barata. Se trataría de una presunción "suave", porque otorgaría libertad total al afiliado para indicar que no desea recibir el servicio, sea por internet, en forma personal o por carta. El Servicio de Búsqueda tampoco sería vinculante, porque cualquier usuario podrá rechazarlo en cualquier momento, por la vía de cambiarse a una AFP elegida por su cuenta, sin pagar multa, aunque sujetándose a los trámites habituales para evitar fraudes y a otras medidas que se indican en la sección 6.3. Estas libertades son una contraparte razonable a la presunción propuesta. Como sabemos que una gran proporción de afiliados no invierte tiempo ni atención en la elección de AFP, es razonable suponer que este servicio será utilizado por la gran mayoría de los beneficiarios de la presunción. Es sólo por efecto de esta presunción legal que el Servicio de Búsqueda evitará los costos del contacto individual. Si el umbral de saldo para presumir que se desea el servicio fuera el monto necesario para comprar una pensión mínima de hombre soltero (unos 16.700 dólares, o Ch. \$ 10 millones), entonces en diciembre de 2004 sólo el 38,3\% de los fondos en las cuentas de ahorro obligatorio habría pertenecido a usuarios objeto de la presunción ${ }^{15}$. Los afiliados con saldo mayor que $\$ 10$ millones en la cuenta individual fueron 786.117. En la sección 6.4 se propone que el umbral de la presunción siempre sea suficientemente bajo para que a lo más el $50 \%$ de los fondos totales sea objeto de la presunción legal.

2. Los usuarios de este servicio serían agrupados en bloques de, por ejemplo, 250.000 cotizantes y otros tantos afiliados no cotizantes (incluyendo pensionados por retiro programado), con un total de 500.000 afiliados cada bloque. La cifra de 250.000 permitiría al menos 10 bloques distintos, y es justificada en la sección 3. Podrían postular AFP nuevas además de las antiguas, poniendo requisitos de experiencia diferentes. La asignación de un bloque a una determinada AFP duraría sólo tres años, y a su término se presumiría que todos los afiliados que continúan en el bloque solicitan nuevamente el servicio de búsqueda, repitiéndose el proceso en forma indefinida.

${ }^{15}$ Usando los datos obtenidos del Boletín SAFP No 183 sobre el número de cuentas según rangos de saldo de la cuenta, p. 52, el monto total del fondo en cuentas de capitalización individual, p. 141, e hipótesis sobre el saldo medio al interior de cada tramo y sobre el saldo medio en las cuentas con más de Ch.\$ 100 millones. Las cotizaciones voluntarias en las cuentas de capitalización individual están incluidas en las cifras de p. 52, pero son menos del $1 \%$ del total de fondos. La suma de Depósitos Convenidos y Cuenta de Ahorro Voluntario (cuenta 2) agrega otro 1,8\% al total de fondos. 
3. Cada tres años habría una licitación de todos los bloques, que la ganarían aquellas AFP que ofrezcan la menor comisión ${ }^{16}$. Habría tres consecuencias: (a) como postular tiene un bajísimo costo para cada postor, no se considerarían gastos comerciales en sus posturas; (b) la altísima sensibilidad de la demanda a las diferencias de comisión entre postores haría que cada postor baje voluntariamente sus comisiones para los usuarios del Servicio de Búsqueda; y (c) la posibilidad de entrar ganando una licitación levantaría una importante barrera a la entrada: la AFP que gane un bloque accedería a muchos afiliados "fieles" (por 3 años), aunque sea nueva.

4. El Servicio de Búsqueda quedaría en manos de una Comisión Supervisora, creada por ley, integrada por cinco expertos financieros, inamovibles y designados por períodos largos. Ellos estarían sujetos a la responsabilidad personal de actuar como haría un hombre prudente con sus propios negocios. La actividad de la Comisión Supervisora sería esporádica, cada tres años, así que no significaría burocracia. La Comisión deberá emitir las bases de la licitación. Para evitar la politización de las licitaciones, esta Comisión sería integrada por mérito, excluyendo a personas afines a partidos y personas relacionadas con las AFP postoras.

La sección 3 muestra que el Servicio de Búsqueda no puede ser exitoso por sí solo. En efecto, las economías de escala en las funciones operativas son tan grandes que permitirían a la AFP más grande ofrecer comisiones mucho más bajas que cualquier otra AFP en las licitaciones. Esa única AFP se llevaría todos los bloques licitados, y el objetivo de desconcentrar la gestión financiera fracasaría. Pero si eso se prohibiera, se privaría a los afiliados de los ahorros que permiten las economías de escala. En respuesta, se propone adoptar dos medidas complementarias: (a) exigir a cada AFP actual desdoblarse en una AFP "pura”, cuyas únicas funciones serían la gestión financiera y el contacto con los afiliados, y en un "operador básico” que cumpla las demás funciones; (b) imponer algunas restricciones adicionales en el Servicio de Búsqueda, que se describen en la sección 6.3 .

\section{Concentración y equidad}

En marzo de 2005 había sólo seis AFP, pero sólo las tres mayores ejercen el liderazgo en la gestión financiera. Ellas asignan casi 60.000 millo-

${ }^{16}$ El plazo entre licitaciones debe ser amplio para evitar la colusión entre postores en el precio. Los bloques deberían licitarse en forma simultánea, para dificultar la colusión. La revelación de las ofertas debería ser simultánea. Se usarían técnicas de remate de unidades múltiples, como las aplicadas en las licitaciones de espectro electromagnético para celulares en EE.UU. 
nes de dólares en activos financieros, un 64\% del PIB de 2004. En el pasado esta concentración ayudó a reducir el grado de control de los principales bancos sobre el costo de financiamiento de las empresas. Ahora que el fondo de pensiones es tanto mayor, esta alta concentración ha empezado a dejar en manos de los gerentes de tres AFP el costo de fondos del sistema financiero chileno. Las inversiones en el exterior de los fondos de pensiones han superado por primera vez las reservas internacionales del Banco Central de Chile, acercando el día en que esos gerentes de tres AFP podrán influir sobre el tipo de cambio. La concentración de las AFP también ha contribuido a reducir la liquidez y el grado de competencia en algunos segmentos del mercado de capitales chileno (ciertos bonos y acciones). Es importante entonces entender las causas de esta elevada concentración.

Es bien sabido y hay amplio consenso en que una de las causas de la concentración es que la ley reserva a las AFP la prestación de un paquete de servicios que incluye actividades con fuertes economías de escala. Desde hace tiempo ha habido propuestas para separar esos servicios. Una segunda causa es el tamaño excesivo del salario imponible máximo y de la tasa de cotización ${ }^{17}$.

Aquí sostenemos que una tercera causa de la concentración es que la ley hasta ahora ha favorecido el contacto individual entre cada AFP y sus afiliados. Para demostrar esta afirmación, describimos un escenario hipotético donde el único servicio que prestan las AFP es la gestión financiera y donde el contacto comercial ocurre por un canal institucional, por ejemplo el Servicio de Búsqueda descrito en la sección 2.4 o empleadores que convocan a licitaciones a nombre de sus empleados. Argumentamos que en ese escenario la industria de AFP estaría mucho más atomizada que hoy.

\subsection{Los costos de las AFP "puras"}

Consideremos un escenario hipotético donde los únicos servicios que presta cada AFP son la gestión financiera y el contacto comercial, pero donde este contacto ocurre por un canal institucional. Esto implica dejar

${ }^{17}$ La tasa de cotización obligatoria, $10 \%$, pretende reemplazar una parte demasiado alta $(70 \%)$ de los salarios para un cotizante de alta densidad, y hasta salarios demasiado altos (3,5 veces el salario medio). En los países anglosajones el ahorro forzoso sólo pretende reemplazar el $50 \%$ del salario o menos, y sólo hasta salarios iguales a 2,0 veces el salario medio. Estas cifras, combinadas con una rentabilidad muy superior a la esperada ( $10 \%$ real en vez de $4,5 \%$ real), ha llevado a un exceso de ahorro stock, que explica en parte la anticipación masiva de las pensiones a edades cercanas a los 55 años. La propuesta de Arrau y Valdés (2002) ataca esta segunda causa de la concentración excesiva. 
fuera de la AFP "pura” los demás servicios que hoy presta una AFP. Esos servicios serían prestados por "operadores básicos", diferentes de las AFP "puras", y son:

1. Contacto individual con los afiliados para lograr su preferencia, utilizando vendedores apoyados por publicidad. Este contacto es reemplazado por un canal institucional. Cuando se permite a cada afiliado dirigir sus inversiones (elegir un multifondo), el costo de la consejería individual queda en manos del canal comercial y de las entidades que prestan los servicios excluidos de la AFP "pura".

\section{Servicios operativos:}

- $\quad$ Recaudación de cotizaciones y pago de pensiones de retiro programado.

- Administración de cuentas individuales, incluyendo cálculo de saldo y producción y distribución de cartolas enviadas a los hogares cada cuatro meses.

- $\quad$ Determinación de pensiones de vejez, incluyendo aportes al SCOMP y pago de subsidios de pensión mínima por cuenta de la Tesorería General de la República.

- Atención de público en red de sucursales y en internet, que pide certificados de saldo, otros certificados, y tramita traspasos de fondos entre multifondos.

- Cuentas de indemnización, sea para empleadas de casa particular u otras.

3. Seguro de invalidez y sobrevivencia, incluyendo el procesamiento de solicitudes de pensión por esos motivos y el financiamiento de las comisiones médicas.

4. Servicios a clientes voluntarios en la Cuenta de Ahorro Voluntario (CAV o "cuenta 2"), que es un fondo mutuo, y en Ahorro Previsional Voluntario (APV). Incluye contacto y asesoría individual.

Las comisiones de una AFP "pura" dependen en parte de los costos, テ que son causados sólo por la gestión financiera y el contacto comercial vía canal institucional. Esos costos incluyen remuneraciones, insumos y el costo del capital necesario para prestar estos dos servicios.

En el caso de la gestión financiera, la experiencia internacional muestra que sus costos son en su mayor parte fijos, en el sentido de que la porción de los costos que varía con el volumen de fondos administrados es minoritaria. Los costos variables incluyen costos de custodia y comisiones de corretaje en bolsa, pero en ambos casos las AFP obtienen fuertes descuentos por volumen, lo que significa que el grueso del costo varía poco con el monto de fondos gestionados. Cuando la AFP delega la gestión de 
parte de los fondos a un administrador "de segundo piso", por ejemplo a un fondo de inversión chileno o a un fondo mutuo accionario extranjero, la ley permite que ese administrador cargue sus comisiones al valor cuota y por tanto a los afiliados, en proporción al saldo que posee cada uno, liberando a la AFP de pagarlas. El principal costo variable por gestión financiera que sufren las AFP chilenas es causado por la regulación que exige a las AFP adquirir y mantener en su activo el $1 \%$ de las cuotas de cada multifondo que administra (esta reserva se llama "Encaje”). Esta reserva es una inversión de bajo riesgo, pero la AFP debe financiarla, sea emitiendo acciones no controladoras o deuda. Los costos de refinanciar el Encaje han sido estimados en una cifra del orden de 100 puntos base al año (Valdés y Marinovic, 2004), lo que aplicado al $1 \%$ implica un costo igual al $0,01 \%$ de los fondos administrados (un punto base al año). Sumando los demás costos de una AFP pura, que varían en función del monto administrado, éstos no pasarían de dos puntos base $(0,02 \%)$ al año.

El grueso de los costos fijos de gestión financiera son las remuneraciones de profesionales de las finanzas e inversiones, la compra de asesorías legales y estudios financieros y suscripciones a fuentes de información especializada. Estos costos fijos aumentan cuando crece el número de límites de inversión y restricciones de cartera que las normas imponen a la gestión de un fondo de pensiones, y aumentan también con el número de fondos gestionados (multifondos). Otro aspecto es que una AFP podría aumentar la calidad de su gestión financiera atrayendo a los mejores estrategos con mayores remuneraciones, y esto se reflejaría en una mayor diferencia entre el retorno alcanzado por los fondos y el promedio de retorno alcanzado por los multifondos comparables. Sin embargo, el costo de este incremento de calidad es de carácter fijo en su mayor parte, pues varía en escasa medida con el volumen de fondos administrados.

Respecto a la inversión comercial para obtener la preferencia de los afiliados, el monto depende crucialmente del canal de distribución utilizado, como se explicó en la sección 2. Los costos comerciales son enormes para una AFP nueva en el escenario actual, que sólo podría atraer nuevos clientes con contactos individuales con vendedores apoyados por publicidad, y sufriría al mismo tiempo la pérdida de algunos clientes a manos de los vendedores de AFP rivales. En ese escenario la inversión comercial supera, lejos, el costo de la gestión financiera. Una parte de esa inversión comercial exhibe economías de escala, en especial en capacitación, supervisión y apoyo publicitario.

En cambio la AFP "pura" utiliza un canal institucional para obtener clientes. Por ejemplo participa en una licitación convocada por el Servicio 
de Búsqueda. Su inversión comercial se limita al costo de postular. También correspondería agregar el costo de las remuneraciones del directorio de la AFP, cuya reputación de honestidad y profesionalismo más allá de toda duda podría ser un insumo necesario para lograr éxito en el canal institucional. Cuando se permite a los afiliados elegir un multifondo, la AFP "pura" asume algún costo comercial adicional, referido a la producción del contenido de la consejería financiera individual. Sin embargo, esa consejería es provista por el canal institucional y por las entidades que presten los demás servicios de la AFP actual.

\subsection{Equilibrio en una industria de AFP "puras"}

Sumando costos, la estructura global de costos de la AFP "pura" estaría dominada por costos fijos, incluyendo entre éstos al costo de oportunidad del capital necesario para financiar los activos de la AFP, ajustado por el riesgo de esos activos. También mantenemos en mente un costo variable según el volumen de fondos administrados, por dos puntos base al año.

Sabiendo que el canal institucional es quien define las bases y tasas de comisión permisibles para los postulantes a la licitación, supondremos en lo que sigue que esta base es la masa de salarios imponibles de los cotizantes. Así, el precio es una tasa única aplicada a esa base. Recordemos que los saldos de las cuentas están altamente correlacionados con el salario imponible, a nivel individual. Si el afiliado mediano del grupo licitado posee un saldo de 25 sueldos imponibles, entonces los dos puntos base al año por gestión financiera equivalen a un costo variable de $0,02 \% \times 25 / 12=$ 0,04\% del salario imponible mensual.

¿Querrá una AFP "pura” invertir en crear un canal comercial basado en contactos individuales, para quitar afiliados a otra AFP que accedió a sus clientes por el canal institucional? Los dueños de la AFP podrían aportar fondos para realizar inversión comercial si ella es rentable. Debido a que el grueso de los costos de la AFP "pura” es fijo, el nivel promedio de la tasa de comisión ganadora deberá ser superior al costo marginal de la AFP según salario imponible del afiliado (0,04\% del salario). Esta diferencia implica que hay un incentivo para invertir en captar un cliente individual de alto margen.

Sin embargo, el costo de contacto individual puede frenar ese incentivo. Según lo indicado en la sección 2, el costo de contacto individual empieza en 0,26\% del salario imponible (para aquellos afiliados de mayor salario, y es mayor para los demás). Sumando el costo variable por gestión 
financiera, concluimos que si la tasa de comisión que gana la licitación es inferior a 0,30\% del salario imponible, las AFP “puras” jamás invertirán en contacto individual. Ésta es la condición para que mantengan sus costos bajos y para que eviten costos comerciales que en parte son fijos y conducen a una concentración creciente.

Consideremos ahora la concentración de equilibrio. Desde luego, la propia competencia creada por la licitación favorece a las AFP "puras” de mayor tamaño, porque pueden distribuir su costo fijo entre más afiliados. Expresado de otra forma, la alta elasticidad precio lograda por la licitación favorece la concentración de la industria de AFP "puras".

Sin embargo, existen por lo menos dos fuerzas que frenan esa tendencia. Primero, es probable que el canal institucional que solicita ofertas esté interesado en una buena calidad de la gestión financiera. La forma estándar de obtener esa calidad es ofrecer una comisión adicional ligada al desempeño financiero logrado por la AFP que esté sobre el promedio de los multifondos comparables (esto se trata en la sección 6.4). En esta situación, la concentración también depende del grado en que el talento de gestión financiera esté concentrado, y de la medida en que este talento sea duradero. La experiencia sugiere que este talento está disperso y es poco duradero. Segundo, debe recordarse que los fondos más grandes sufren más dificultad para cambiar su cartera, sin provocar movimientos en los precios adversos a su retorno, que los fondos menores. Estas dos fuerzas favorecen la atomización de la industria de AFP "puras".

Consideremos una industria donde cada AFP "pura" tiene un costo fijo de 1,5 millón de dólares al año. Según se observa en los estados financieros de las Administradoras de Fondos Mutuos chilenas, éste es un valor plausible para el costo de un equipo de ejecutivos financieros más personal de apoyo, que utiliza algunos recursos en común con un grupo financiero o bancario al cual pueda pertenecer. El lector podrá replicar los cálculos que siguen con cualquier otro nivel de costo fijo que le parezca interesante. Consideremos también una comisión de 0,30\% del salario, de lo cual 0,26 puntos son margen. En este escenario, se encuentra que cada AFP "pura" requiere una clientela de al menos 40.000 cotizantes con un salario imponible medio de 1.200 dólares (40 UF) para cubrir sus $\operatorname{costos}^{18}$. En Chile el 33\% de quienes están obligados a cotizar labora en organizaciones con más de 200 empleados, que podrían utilizar el canal institucional. Si la mitad de esos cotizantes participara en este canal, se trataría de 567 mil personas, y esta cifra acomodaría un máximo de catorce (14) AFP “puras” de igual tamaño.

${ }^{18}$ El cálculo es $\mathrm{N}^{\circ}$ clientes = (Costo Fijo Anual/12)/(tasa de comisión de 0,26\% x Salario Imponible Mensual). 
Sin embargo, si alguna AFP "pura” duplica ese tamaño, podría reducir su comisión a casi la mitad (a 0,04 +0,26/2 =0,17\%). Si bien algunos empleadores pueden estimar que esta ventaja es contrarrestada por una gestión financiera talentosa que explota la ventaja del tamaño pequeño, la realidad es que el talento y esa ventaja son escasos y transitorios. De esta forma, aquella AFP pura que crezca un poco más podrá adoptar una política agresiva de postulaciones destinada a ganar más contratos y aprovechar las economías de escala, para crecer más y bajar sus costos medios, concentrando la industria. Las AFP "puras" que siguieran esa política podrían reducir las comisiones bastante por debajo de $0,30 \%$ del salario, manteniendo a la vez una gestión financiera de calidad aceptable.

La conclusión es que un canal institucional construido en torno a empleadores que cubra el $17 \%$ de los cotizantes podría sustentar unas cuatro o cinco AFP adicionales a las actuales, que servirían al resto de los afiliados por medio de contactos individuales. Desde luego, esa conclusión varía si se permitiera a las AFP existentes participar en el canal institucional con comisiones diferentes de las que aplican a sus demás afiliados. En ese caso, las AFP existentes aprovecharían su gran tamaño para ganar todo el canal institucional, manteniendo los actuales niveles de concentración.

De otro lado, también queda claro que si los canales institucionales incluyeran al Servicio de Búsqueda propuesto en la sección 2.4 y cubrieran a tres cuartos de los cotizantes, lo cual significaría reducir el salario imponible promedio a sólo 600 dólares al mes (20 UF), una industria de AFP "puras” podría acomodar una dispersión significativa de la gestión financiera. En efecto, en ese escenario el máximo teórico de AFP "puras" de igual tamaño aumenta a treinta y uno. Específicamente, si el Servicio de Búsqueda ofrece bloques de 250 mil cotizantes (y otros 250 mil afiliados que no cotizan), con un salario imponible medio de 300 dólares al mes (10 UF), la comisión requerida para financiar los costos de las AFP "puras" sería sólo $0,21 \%$ del salario, bastante menor que el costo de contacto individual. Aun considerando la estrategia de rebajar comisiones, esta cifra podría sustentar un grado de dispersión claramente superior al actual. En la sección 6.3 se proponen regulaciones que garantizan que la concentración disminuya.

Si el contacto comercial de las AFP "puras" fuera de carácter individual, parecería haber dos efectos contrapuestos sobre la concentración. Desde luego, una parte de la inversión comercial exhibe economías de escala en capacitación, supervisión y apoyo publicitario, aumentando la concentración de la industria, que sería mayor en equilibrio ${ }^{19}$. Sin embargo, el con-

${ }^{19}$ Éste es el "costo fijo endógeno", analizado en detalle por Sutton (1991). Ese autor demostró empíricamente su importancia práctica en numerosas industrias que venden al consumidor masivo. 
tacto individual implicaría dejar la elección de AFP a clientes insensibles a las comisiones (ver sección 2), lo que impediría que la estrategia de rebajar comisiones atrajera clientes. La experiencia demuestra que la estrategia de rebajar comisiones sería sustituida por una política de fusiones entre AFP, pues ellas permiten aprovechar las economías de escala sin necesidad de rebajar comisiones. De esta forma, sólo subsiste el primer efecto sobre la concentración de equilibrio, que es al aumento. En conclusión, el contacto individual favorece la concentración de la gestión financiera, como se afirmó.

\subsection{La demanda social por comisiones equitativas}

Existe una demanda social de que la estructura de comisiones de las AFP sea "equitativa”. Nos referimos a la demanda de que el monto de la comisión decrezca proporcionalmente al caer el salario del afiliado. Aquí justificamos la existencia de esta demanda social y describimos formas alternativas de satisfacerla. Luego, en la sección 3.4 mostramos que esta demanda ha sido una cuarta causa de la concentración en la gestión financiera de las AFP.

Esta demanda social nace de la obligación legal de adquirir servicio a alguna AFP, que convierte a la comisión de AFP en un impuesto. Los impuestos están sujetos a criterios de equidad. En cambio, aquellos servicios de demanda voluntaria que dan al potencial cliente la opción de no comprar, tienen un precio liberado de exigencias de equidad. El caso de los servicios básicos como agua potable y distribución eléctrica sería intermedio, porque la opción de no comprar es discutible. Eso mismo explicaría que la ley utilice criterios de equidad para fijar el monto del cargo fijo en la tarifa.

La reforma de 1980 dio dos respuestas simultáneas a esta demanda. La primera fue exigir a cada AFP aplicar tasas de comisión uniformes a todos sus afiliados, dentro de cada tipo de comisión. Sin embargo, como uno de los tipos de comisión era la comisión fija ${ }^{20}$, cada AFP quedó facultada para eludir la demanda social. Para eludirla bastaba con usar la comisión fija para financiar los costos fijos y utilidades, y con usar la tasa de comisión aplicada al salario para financiar los costos proporcionales al salario imponible (sobre todo la prima del seguro).

La otra respuesta fue disponer que la comisión fija se restara del saldo de la cuenta individual y no del salario líquido. Esto interactúa con el

${ }^{20}$ Hasta 1987 hubo dos comisiones adicionales, aplicadas al saldo, pagadas por los afiliados no cotizantes. Una de ellas era fija y la otra un porcentaje del saldo. A partir de 1988, una ley prohibió las comisiones sobre saldo. 
"subsidio de pensión mínima" otorgado a quienes no autofinancian una pensión igual a la meta de pensión mínima que establece el Estado. En efecto, si el cotizante resulta ser merecedor del subsidio de pensión mínima, el fisco termina pagando el 100\% de la comisión fija. Esta vía también fue adoptada por la reforma de 1980, en forma paralela a la uniformidad de la tasa de comisión.

Sin embargo, esta segunda vía resulta inequitativa, por tres razones: (i) no ayuda en nada a los realmente pobres, que en su mayoría no alcanza a reunir los 20 años de cotizaciones requeridos para acceder al subsidio de pensión mínima; (ii) muchos receptores del subsidio de pensión mínima no son pobres, por ejemplo mujeres profesionales que trabajan jornada parcial y cuyo nivel de vida está fuertemente influido por el salario del marido; y (iii) muchos obreros de bajo ingreso pero alta densidad autofinancian una pensión levemente superior a la mínima, pero no reciben ayuda alguna del Estado para defenderse de la comisión fija. Quizá esto explique por qué a lo largo de los años 80 el gobierno chileno optó por empujar hacia una reducción de la comisión fija.

En efecto, si bien se observó que las comisiones fijas fueron bastante altas en relación con el salario mínimo en los años 80 , fueron decayendo gradualmente a medida que la demanda social era satisfecha en mayor grado por la primera vía indicada. En el período 1983-1987, el gobierno aprovechó su toma de control de los grupos económicos que habían creado las principales AFP para ordenar que la comisión fija se reajustara menos que la inflación (ésta superó el 20\% anual). En ciertos casos, el gobierno aplicó una fiscalización punitiva a aquellas AFP que se negaban a bajar su comisión fija. En los años 90 muchas AFP eliminaron o redujeron voluntariamente su comisión fija con el fin de mejorar su imagen pública. La solidaridad aparente que resultó de estas normas y prácticas es un factor que ayuda a explicar la decisión adoptada por los gobiernos chilenos posteriores a 1990 de aceptar el sistema de AFP. El carácter general de esta demanda social se manifestó también en lo siguiente: cuando Bolivia, Colombia y El Salvador crearon sus sistemas de AFP, sus leyes prohibieron la comisión fija.

Existen otras alternativas para satisfacer la demanda social por comisiones equitativas. Una consiste en crear un subsidio fiscal al ingreso de los cotizantes pobres, distribuido mediante una red social que evalúa la pobreza a nivel individual. En presencia de ese subsidio, se aceptarían las comisiones que resulten de la competencia, sin objetar su posible regresividad. Ésta es la política general respecto al precio de los alimentos básicos, la telefonía celular y casi todos los demás servicios. Notemos que el subsidio se financia con aumentos en las tasas generales de impuesto, parte de 
las cuales recaen sobre contribuyentes no cotizantes ${ }^{21}$. Además, el incremento de la tasa en los impuestos generales es menor que una comisión que recae únicamente sobre cotizantes, y por ello las distorsiones son menores. Sin embargo, el subsidio nunca ha sido aplicado en los sistemas privados de pensiones. Una razón es que resulta incompatible con el hecho de que las AFP tengan libertad de precios, pues podrían elevar las comisiones sabiendo que el Estado las paga, sin que el cotizante ponga objeción alguna.

Otra alternativa para satisfacer la demanda social por comisiones equitativas es usar impuestos y subsidios para redistribuir al interior del sector o industria. En este caso la redistribución no está acotada a los cotizantes de una misma AFP, como ocurre con la política que ha dominado desde fines de los años 80. En esta última se exige que cada AFP tenga una única tasa de comisión, que se aplica sólo a los cotizantes de esa AFP. Si estas tasas son iguales entre las AFP, entonces aquellas cuyos cotizantes tienen un mayor salario imponible reciben rentas adicionales. En cambio, en la alternativa discutida aquí, el margen que deja un cotizante de alto salario es captado por impuestos, cualquiera sea la AFP que elija, y es redistribuido a todos los demás cotizantes por medio de subsidios.

\subsection{Tasa única de comisión en cada AFP y concentración de la gestión financiera}

Esta sección sostiene que otra causa para la elevada concentración en la gestión financiera de las AFP ha sido la respuesta que dominó desde los 80 a la demanda social por comisiones equitativas. La regulación que obliga a cada AFP a elegir una tasa única de comisión (que es un porcentaje del salario), y que puede diferir entre las AFP, tiene tres consecuencias:

(a) La tasa única de comisión empuja los costos al alza, de manera de reducir la solidaridad efectiva en las comisiones, incumpliendo la demanda social.

(b) La tasa única de comisión empuja los costos fijos al alza, induciendo un aumento de la concentración en la gestión financiera de las AFP.

(c) En algunos casos, la tasa única de comisión permite que surjan AFP especializadas en cotizantes de altos ingresos, lo cual refuerza el resultado (a) sin afectar el resultado (b).

${ }^{21}$ No es la única opción, pues el subsidio también podría ser financiado por los cotizantes de altos ingresos. Valdés (1995) propone eliminar las ventajas tributarias que hoy se otorgan a los contribuyentes para pagar comisiones a las AFP, pues están exentas del impuesto a la renta personal, y además están exentas de IVA. 
Analicemos el punto (a). La tasa única de comisión exige a cada AFP practicar una fuerte discriminación de precios entre sus propios cotizantes. Recordemos que la discriminación de precios es aquella situación donde una firma que sirve a dos clientes distintos aplica una diferencia de precios de magnitud distinta de la diferencia entre los costos marginales de prestarles servicio. Lo relevante para medir la discriminación es el costo marginal, no el costo medio.

En el Chile de 2004, el costo marginal de servir a un cotizante más fue estimado en aproximadamente \$500/mes, excluyendo la prima del seguro de invalidez y sobrevivencia, para una AFP grande ${ }^{22}$. Para un cotizante de alto ingreso (60 UF/mes), el margen se estima en \$ 220.800 al año, pero para el afiliado que declara el salario mínimo (\$119.000 al mes), el margen se estima en $\$ 1.250$ al año, considerando las diferencias de costos marginales ${ }^{23}$. Como la diferencia de comisiones es cinco veces la diferencia de costos, la discriminación resulta muy fuerte $\mathrm{e}^{24}$.

A su vez, esta discriminación impuesta por ley incentiva a cada una de las AFP a ejecutar toda clase de estrategias para captar a los clientes de alto margen, o al menos para no perderlos. Ellas van desde hacer regalos en dinero hasta otorgar servicios de asesoría tributaria, CAV gratis y APV a precios bajo el costo. Estas estrategias se implementan a través de vendedores, quienes no pueden ser fiscalizados por la Superintendencia. También se implementan enviando literatura financiera por correo, pero a los afiliados de alto ingreso solamente, y desarrollando páginas de internet basadas en banda ancha, que sólo esos afiliados tienen. Debido a la focalización de estas estrategias, ellas reducen la verdadera equidad de la tasa única de comisión, incumpliendo la demanda social. Además, estas estrategias son ineficientes cuando el servicio extra prestado al cliente privilegiado es valorado por éste en menos que el costo marginal de producirlo.

${ }^{22}$ Las funciones de costo estimadas por Marinovic y Valdés (2004) permiten estimar el costo marginal de servir a un paquete adicional integrado por un cotizante y un afiliado no cotizante. Éste es aproximadamente \$ 800/mes en las AFP grandes. Se sabe que el cotizante es más caro porque servirlo requiere servicios de recaudación, proceso de seguros y dos cartolas más al año. Luego, el costo del paquete puede dividirse en \$ 500 por el integrante que cotiza y $\$ 300$ por el no cotizante.

${ }^{23}$ Estos cálculos usan los siguientes supuestos adicionales: la tasa de comisión es $2,3 \%$, la prima del seguro para cotizantes ricos y pobres es $0,50 \%$ y $1,00 \%$ respectivamente, y la densidad de cotización es $100 \%$ y $30 \%$ para el rico y pobre respectivamente. El cálculo para el pobre es: Margen $=12$ meses $*[(0,023-0,010) * 119.000 * 0,30-$ $(0,30 * 500+0,7 * 300)]=1 \cdot 249,27$ (\$/año). Es el mismo método para el rico. Como el margen del pobre parece levemente positivo, podría ser falsa la difundida creencia de que los cotizantes de bajo ingreso reciben un "subsidio cruzado".

${ }^{24}$ Diferencia de precios: $12 * 0,023 *(1.050 .000-119.000)=\$ 256.956$ /año; Diferencia de costos es $12 *[(0,005 * 1.050 .000+500)-(0,010 * 119.000+0,3 * 500+$ $0,7 * 300)]=\$ 50.400 / \mathrm{año.}$ 
Los costos son empujados al alza por tres razones: primero, el contacto individual tiene un costo significativo, que es necesario asumir para distribuir estos beneficios focalizados. Segundo, los beneficios también tienen un costo de producción. Tercero, no todo el margen es devuelto al afiliado de alto ingreso por la vía de regalos y servicios extra, pues una parte es captada por la AFP, siendo éste el cebo para otorgar beneficios focalizados. Si bien podrá haber una AFP que destine todo el margen neto a financiar costos fijos, siempre habrá utilidades sobrenormales para las AFP inframarginales.

A continuación justificamos el punto (b). Los efectos de estas estrategias sobre la concentración de la gestión parecen ambiguos, pero no lo son en definitiva. Parte de los nuevos costos comerciales son fijos (entrenamiento, supervisión, publicidad) y parte de los costos de producción de beneficios focalizados son fijos, porque hay economías de escala. Los componentes fijos del alza de costos contribuyen a concentrar la gestión financiera de las AFP.

Por último, analicemos el punto (c). Cuando existen bajas barreras a la entrada a la industria de AFP, puede ser posible eludir el efecto solidario buscado por la ley al imponer una tasa única de comisión a cada AFP, con otra estrategia: especializando a cada AFP en un segmento de ingresos diferentes. Las AFP especializadas en afiliados de altos ingresos protegen a éstos de la discriminación de precios, cobrando una tasa de comisión menor, como ocurre en Argentina ${ }^{25}$. Es obvio que esto incumple la demanda social por comisiones equitativas.

Respecto a los costos, esta estrategia estimula la entrada de AFP de pequeña escala, e incluso ineficientes por tecnología, pues ellas pueden sobrevivir al alero de los márgenes altos cobrados a los cotizantes de alto ingreso. Esto parece favorecer la atomización de la gestión financiera. Sin embargo, los dueños de las AFP especializadas ganan al fusionarse con otras, pues aprovechan las economías de escala. Las fusiones - también observadas en Argentina - cancelan el efecto de la entrada en pequeña escala, que era favorable a la atomización. De esta forma, el efecto de largo plazo de esta estrategia es aproximadamente neutro respecto a la concentración, como se afirmó.

Recordemos la alternativa de satisfacer la demanda por comisiones equitativas que usa impuestos y subsidios para redistribuir entre todos los

${ }^{25}$ Hay dos razones que ayudan a explicar por qué esto no ocurre en Chile: (i) el número absoluto de empleados de altos ingresos es menor en Chile; y (ii) el salario imponible máximo es menor en Chile, y esto reduce el margen que puede captar una AFP especializada en cotizantes de alto ingreso. Ambas son importantes debido a las economías de escala. 
cotizantes. Como el margen que deja un cotizante de alto salario es captado ahora por impuestos, cualquiera sea la AFP que elija, y es redistribuido a todas los demás cotizantes por medio de subsidios, no hay incentivos para que cada AFP individual adopte estrategias para atraer afiliados de alto salario. También elimina los incentivos para crear AFP especializadas en cotizantes de alto salario. Así, esta alternativa elimina la tendencia a aumentar costos, parte de los cuales son fijos, y por tanto evita la tendencia a concentrar la gestión financiera. En la sección 6 se propone adoptar una variante de esta alternativa.

\section{Consecuencias de estos vacíos de diseño}

Las secciones anteriores identifican un vacío y una falla en el diseño del sistema de AFP. El vacío es aquella asimetría en la intervención del Estado, que niega ayuda institucional efectiva para comparar comisiones de AFP, pero obliga a adquirir el servicio de AFP. La falla es que la demanda social por comisiones equitativas ha sido enfrentada imponiendo una tasa de comisión única como porcentaje del salario en cada AFP. Esta sección recuerda cómo desde 1993 cundió en Chile la preocupación porque la industria de AFP gastaba en vendedores mucho más de lo justificable como beneficio para sus afiliados. Esta tendencia fue causada por el vacío y la falla descritos, y empujó al gobierno a intervenir en 1997 con medidas de corte neocorporativista.

\subsection{Ineficiencia creciente}

La ausencia de ayuda efectiva para comparar comisiones permitió a cada AFP elevar su comisión regular perdiendo un número ínfimo de clientes. Pero como cada AFP hacía lo mismo, la comisión promedio tendía a subir o mantenerse en niveles altos ${ }^{26}$. Esto elevó el margen medio. Una consecuencia es que el alto margen hace rentable que cada AFP que actúa en forma independiente, invierta sumas mayores en vendedores, publicidad,

${ }^{26}$ Hay tres mecanismos que impiden el aumento ilimitado de comisiones: (a) una comisión absoluta alta permite que métodos alternativos de información respecto a precios, que elevan la elasticidad precio, pasen a ser viables; (b) un alza adicional induciría la entrada de la AFP aspirante de menor costo. Las AFP titulares están dispuestas a sacrificar precio para evitarlo si la industria está concentrada (precio límite); (c) las altas comisiones elevan el riesgo de intervención de la autoridad, amenazando el valor económico de todas las AFP (por ej. imponer precios máximos, como en Colombia y El Salvador, o abrir la opción de volver al sistema antiguo, como en Colombia). Las AFP titulares están dispuestas a sacrificar precio para evitarlo si la industria está concentrada. 
calidad de servicio, sorteos, y rebajas en productos vendidos en forma cruzada. El margen también aumentó debido a la respuesta ineficiente a la demanda social por comisiones equitativas, como se mostró en la sección $3.4^{27}$.

Esto explica en parte la competencia comercial de alto costo y altísima rotación, en presencia de entrada de nuevas AFP, observada en 19811982 y 1991-1997 (Gráfico Nº 1). El Gráfico No 2 muestra que en 1991-1997 subían las comisiones absolutas, alimentando el aumento en el número de vendedores.

\section{GRÁFICO No 1 : VENDEDORES Y TRASPASOS EN CHILE}

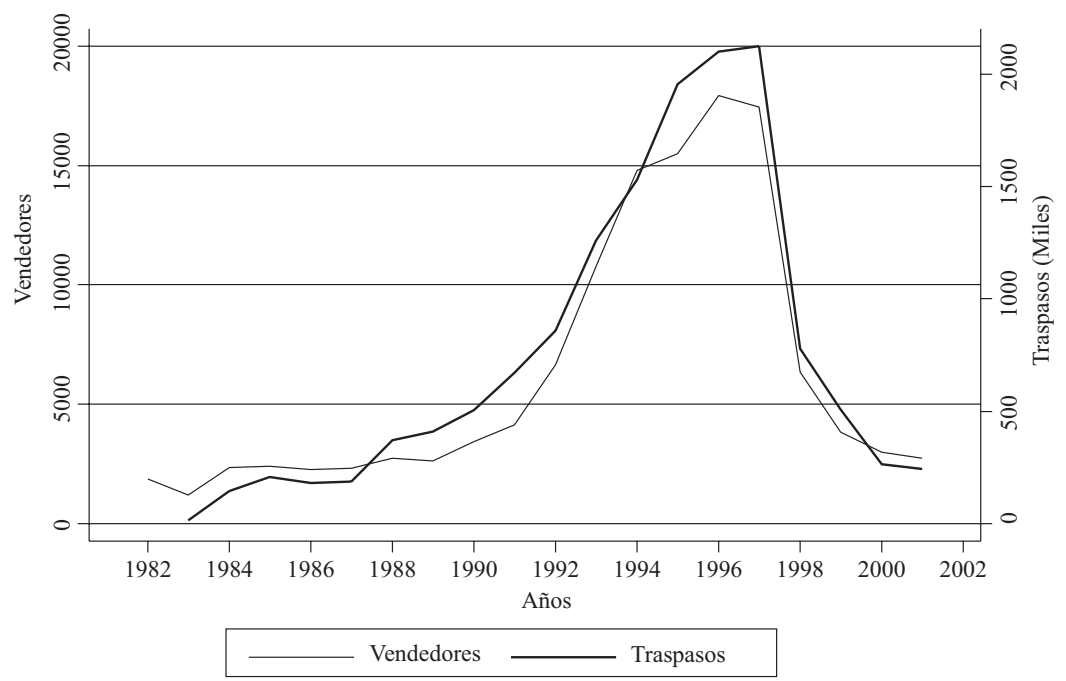

Fuente: Superintendencia de AFP.

Otra consecuencia de un margen alto es la entrada de operadores ineficientes. A principios de los 90 entraron varias AFP con gestión poco profesional y a escala modesta, que no tomaron en cuenta las barreras económicas que las expulsarían más adelante. Mientras operaron, elevaron los costos y destruyeron riqueza.

En el período de alta rotación comercial hasta 1997, la comisión neta subió. Esto se explica en parte porque el fuerte aumento en el salario imponible medio que trajo el auge económico de la época, no fue acompañado de

${ }^{27}$ No es efectivo que los regalos de vendedores "licuen” el ahorro obligatorio, mientras la comisión fija esté acotada. Si la AFP eleva la comisión porcentual sobre el salario, reduce el salario líquido del cotizante, sin afectar al fondo de pensiones. 




Nota: Para 1998 se muestra sólo la interpolación de las cifras para 1997 y 1999. No se muestra la cifra efectiva para 1998 porque el despido de más de diez mil vendedores en ese año gatilló el pago de un gran monto en indemnizaciones.

una rebaja equivalente en la tasa de comisión, neta de regalos. El costo económico medio también subió porque el gasto en vendedores aumentó, y por la entrada de operadores de pequeña escala. Interpretamos el episodio de 1991-1997 como un caso donde el vacío y la falla identificados en las secciones anteriores elevaron las rentas de las AFP, pero ellas fueron disipadas (en parte) por la vía de aumentos en el costo comercial y a través de una entrada ineficiente.

El cotizante medio paga la suma de la comisión neta y la prima del seguro (líneas gruesa y punteada, respectivamente, en el en el Gráfico No 2.) La diferencia entre las líneas gruesa y delgada estima la utilidad sobrenormal de las AFP.

Otro indicador importante es la rentabilidad sobre sus propios activos económicos que obtienen las AFP (no sobre el fondo de pensiones). El Cuadro 1 muestra los resultados de una estimación reciente de esta rentabilidad (Valdés y Marinovic, 2004). La estimación se basa en la contabilidad pública de las AFP, pero difiere de ella por tres ajustes: primero, separa otros negocios diferentes de la AFP, como inversiones en el DCV y en AFP extranjeras. Segundo, separa los activos de bajo riesgo que diluyen la rentabilidad efectiva del negocio puro de AFP. Si bien es obvia la separación del Encaje, activo de bajo riesgo refinanciable por la AFP a costos moderados, 
también reconoce como costo corriente el valor esperado de la multa que la AFP debe pagar cuando el retorno de un fondo de pensiones perfora el piso de la rentabilidad mínima, multiplicado por la probabilidad de que se incurra en multa. Tercero, reconoce que las AFP poseen activos intangibles que deben ser sumados a los activos habituales. El principal de estos intangibles representa el costo de adquirir los clientes que enfrenta cada nueva AFP cuando entra, bajo la hipótesis de competencia comercial. Esta hipótesis es crucial, pues la diferencia de rentabilidad entre suponer que cada nueva AFP supera las barreras a la entrada creadas a partir de 1998, y suponer que cada nueva AFP adquiere sus nuevos clientes bajo condiciones de competencia, es una medida de la magnitud de la barrera a la entrada ${ }^{28}$.

El Cuadro 1 también estima la rentabilidad normal como igual a la tasa de interés de los bonos de largo plazo libres de riesgo, más 5 puntos porcentuales anuales. Esta regla implica una rentabilidad normal para las AFP de 11,5\% anual real en el año 2000, cifra que supera en casi dos puntos al 9,6\% que se aplicó en ese año para definir las tarifas del servicio de agua

CUADRO No 1 RENTABILIDAD SOBRE ACTIVOS: INDUSTRIA DE AFP, 1996-2003

(Antes de impuesto de primera categoría)

\begin{tabular}{|c|c|c|c|c|}
\hline Año & $\begin{array}{c}\text { ROA económico } \\
\text { observado en AFP } \\
\text { (\% anual real) }\end{array}$ & $\begin{array}{c}\text { Diferencia en \$ con } \\
\text { rentabilidad normal } \\
\text { (Mill. \$ de } \\
\text { diciembre 2003) }\end{array}$ & $\begin{array}{l}\text { Diferencia con } \\
\text { rentab. normal } \\
\text { (Mill. dólares) }\end{array}$ & $\begin{array}{c}\text { Caída en la comisión } \\
\text { si ROA cae a R. normal } \\
\text { (Puntos de } \\
\text { salario imponible) }\end{array}$ \\
\hline
\end{tabular}

$\begin{array}{rrrrr}1993 & 10 \% & -2.102 & -3,5 & -0,03 \\ 1994 & 9 \% & -2.398 & -4,0 & -0,03 \\ 1995 & 27 \% & 17.740 & 29,4 & 0,22 \\ 1996 & 23 \% & 14.981 & 24,8 & 0,17 \\ 1997 & 22 \% & 14.899 & 24,7 & 0,16 \\ 1998 & 26 \% & 16.533 & 27,4 & 0,17 \\ 1999 & 35 \% & 24.674 & 40,9 & 0,25 \\ 2000 & 51 \% & 42.494 & 70,5 & 0,42 \\ 2001 & 68 \% & 61.712 & 102,4 & 0,58 \\ 2002 & 63 \% & 65.677 & 108,9 & 0,60 \\ 2003 & 48 \% & 47.054 & 78,0 & 0,43\end{array}$

Fuente: Cuadro $\mathrm{N}^{\circ} 4$ en Valdés y Marinovic (2004), página 42. El tipo de cambio promedio de diciembre de 2003 fue \$ 602,9 por un dólar, y se usó para obtener la tercera columna a partir de la segunda.

${ }^{28}$ Cualquier evaluación del proyecto de crear una nueva AFP después de 1998 arrojaría una rentabilidad insuficiente para atraer accionistas, si supusiera que se debe invertir todo lo necesario para superar la barrera a la entrada existente. 
potable en Santiago (Aguas Andinas ${ }^{29}$ ) para el período 2000-2004. Una rentabilidad "normal" de $12 \%$ anual permite la coexistencia de tasas de rentabilidad sobre activos de $18 \%$ para las AFP más eficientes (ROE de $26 \%$, considerando un grado normal de endeudamiento ${ }^{30}$ ), con rentabilidades de $6 \%$ para las AFP menos eficientes (ROE de 6\%). Éste es un nivel de referencia que respeta las rentas sobrenormales que obtendrían las AFP con capacidades relativas superiores en una competencia verdadera.

Conviene precisar que el activo económico de una AFP no tiene relación directa con el precio pagado por algunos de los dueños actuales de las AFP cuando las adquirieron. Ese precio probablemente incluyó el valor presente esperado de una renta sobrenormal, cuya permanencia es una mera expectativa, no un derecho adquirido. Si un aumento de competencia devuelve la rentabilidad al nivel normal, sólo se habrá probado la buena suerte de los antiguos dueños que vendieron a buen precio.

\subsection{Explicaciones estratégicas para los hechos posteriores a 1997}

A partir de noviembre de 1997 el equilibrio de la industria cambia drásticamente (ver Gráficos $\mathrm{N}^{\circ} 1$ y 2 y Cuadro $\mathrm{N}^{\mathrm{o}} 1$ ), indicando una fuerte caída de costos y un fuerte aumento en las utilidades sobrenormales. Hay dos familias de explicaciones para este enorme cambio. La primera es el neocorporativismo, y la segunda reúne a ciertas hipótesis estratégicas. Esta sección muestra que esta segunda familia de explicaciones es contradicha por los hechos.

La primera hipótesis estratégica es que el proceso de fusiones hace que un mayor número de AFP tome en cuenta las posibles reacciones de los rivales cuando ella contrata un vendedor más. Resulta que cuando los rivales despiden vendedores, la reacción óptima para cada AFP individual podría ser despedir también, según como sean los detalles de la situación ${ }^{31}$. Este efecto es mayor cuando la industria se concentra más. Esto último implica que un proceso de fusiones haría que el nuevo equilibrio estratégico con actuación independiente entre AFP exhiba menos vendedores. Sin em-

${ }^{29}$ Fuente: El Mercurio de Santiago, 9 de marzo 2004, p. B1. Ese artículo indica además que la tasa de costo de capital para Aguas Andinas bajará a 7,7\% real anual para el período 2005-2009.

${ }^{30} \mathrm{La}$ rentabilidad sobre patrimonio (ROE) es función de la rentabilidad sobre activos (ROA), del endeudamiento y de la tasa de interés del crédito. En el caso de un $40 \%$ de endeudamiento, suponemos que el crédito costaría $6 \%$ real anual, debido a la baja correlación entre el retorno del negocio AFP y el retorno del portfolio de mercado. Si ROA $=12 \%$, entonces $\mathrm{ROE}=16 \%$.

${ }^{31}$ En este caso se verifica la propiedad de "complementariedad estratégica”. 
bargo, esta explicación también predice que las AFP que crecen más debido o que participaron en fusiones, reducen sus vendedores en mayor grado. Los hechos contradicen esta predicción, porque todas redujeron sus vendedores en igual proporción en 1998-1999, cualquiera fuera su tamaño.

La segunda hipótesis es que varias AFP grandes siguieron una estrategia predatoria, en forma independiente unas de otras. Si las AFP grandes y antiguas elevan la rotación sobreinvirtiendo en vendedores, con el fin de perjudicar a las AFP más nuevas cuya clientela es más infiel y rota más rápido, las primeras podrán adquirir a menor precio las AFP más nuevas. Una vez ocurridas las fusiones, viene el momento de cosechar, lo cual implica detener esa sobreinversión y despedir a los vendedores. Sin embargo, la predación es tal sólo cuando el valor presente esperado de contratar un vendedor es negativo, y la evidencia muestra que era positivo. Además, la reducción de vendedores de 1998 habría estado acotada, porque una menor rotación de clientes implica una mayor permanencia de cotizantes nuevos, y esto aumenta los incentivos a gastar en vendedores. Luego, esta hipótesis sólo explicaría un despido limitado de vendedores. La evidencia muestra lo contrario. Además, esta hipótesis implica que las AFP grandes y antiguas que habrían seguido la estrategia predatoria redujeran sus vendedores en mayor proporción que las AFP chicas sobrevivientes, pues la predación nunca habría sido atractiva para éstas últimas. La evidencia contradice esta predicción.

Tercero, consideremos estrategias en torno a remunerar a los vendedores por "mantención”, es decir según la permanencia efectiva de los afiliados que traspasen, en vez de remunerarlos por los meros traspasos, sin condiciones. Se observó que en 1998-1999 todas las AFP grandes, pero no las pequeñas, adoptaron un esquema de remuneración a vendedores según permanencia. Es sabido que los vendedores remunerados por el mero traspaso son más exitosos que aquellos remunerados por permanencia efectiva, cuando los compromisos de permanencia están prohibidos. Ello implica que, si todas las demás AFP remuneran a sus vendedores por permanencia, cualquier AFP chica tendrá fuertes incentivos para remunerar a los suyos por el mero traspaso. En cambio, respecto a las AFP grandes, cada una tomará en cuenta que si remunera a sus vendedores según traspasos, las demás responderán adoptando ese mismo esquema de remuneración, con el resultado final de elevar los costos y perder valor. Luego, la factibilidad de coordinarse para adoptar el esquema de remuneración por permanencia depende de la concentración de la industria. La hipótesis es que cuando la ola de fusiones de 1996-1999 elevó la concentración, se habría hecho viable una coordinación en esta decisión entre las AFP grandes. Sin embargo, esta explicación implica que aquellas AFP que continúen remunerando el mero traspaso cre- 
cerán y aumentarán su contratación de vendedores, mientras que las que remuneran por permanencia vivirán la situación opuesta. Estas predicciones no se cumplieron, porque las AFP chicas despidieron vendedores al mismo ritmo que las AFP grandes.

La cuarta hipótesis es que el despido masivo de vendedores fue una respuesta a las circulares 988 y 998, de noviembre de 1997, que exigieron fotocopia de la cartola y una visita a la agencia de la AFP para cambiarse. Estas circulares fueron útiles, porque eliminaron fraudes de los vendedores. Ellas redujeron también la productividad física de los vendedores (el número medio de traspasos por mes), pero la reducción debe haber sido modesta, porque cuando se derogaron circulares análogas en 1988, el impacto sobre el número de traspasos fue pequeño. La caída de productividad física no puede explicar el masivo despido de vendedores, porque en presencia del enorme aumento en el tiempo medio de permanencia de un nuevo afiliado a partir de 1997, la productividad monetaria de un vendedor se multiplicó muchas veces. Esto prueba que el despido de vendedores fue mucho más allá de lo justificado por una reducción en la productividad física. El rol de estas circulares parece haber sido desviar la atención de los medios de comunicación desde las circulares importantes, la 999 y 1.051.

Quedan descartadas entonces las hipótesis estratégicas para explicar el despido masivo de vendedores registrado a partir de noviembre de 1997. La única forma de explicarlo es el neocorporativismo (ver próxima sección).

\section{Neocorporativismo en 1998-2001}

A fines de 1997, la ineficiencia comercial de las AFP había aumentado hasta resultar indefendible. La autoridad se sentía políticamente obligada a intervenir. ¿Es conveniente que la autoridad ayude a las AFP a reducir costos, mediante la cooperación en una menor contratación de vendedores, pero que exija a cambio que ellas bajen las comisiones regulares a los afiliados?

\subsection{Las circulares 999 y 1.051}

La Circular N 999 de noviembre de 1997 prohibió contratar más vendedores $^{32}$. Esto impidió que aquellos vendedores despedidos por una AFP fueran contratados por otra. En general, esto alienta a cada AFP que

${ }^{32}$ Prohibió contratar vendedores mientras éstos no hubiesen aprobado un examen. Dicho examen se tomó el 27 de julio de 1998, de manera que no hubo exámenes durante ocho meses. 
actúe en forma independiente a despedir vendedores, pues da la seguridad de que ningún rival podría contratarlos, y da seguridad de que cuando un rival despida, no podrá recontratar. La circular 999 también bloqueó la entrada, porque cuando se prohíbe contratar vendedores, toda potencial nueva AFP queda fuera del mercado. En general, bloquear la entrada favorece la actuación colusiva, pues alarga el horizonte de cualquier acuerdo.

La Circular $\mathrm{N}^{\circ}$ 1.051, del 30 de octubre de 1998 reemplazó a la º 999. Esta insólita circular exigió a cada AFP que deseara contratar uno o más vendedores, avisar de este plan con anticipación a todas las AFP rivales, identificando además a cada uno de los vendedores que deseaba contra$\operatorname{tar}^{33}$. Es evidente que con esta circular la autoridad proveyó la información que era necesaria para sostener la cooperación en la compra de servicios a los vendedores. Debe destacarse que en general los carteles para reducir el gasto de marketing son poco exitosos porque las variables de marketing son muchas y difíciles de observar en forma objetiva. Esta dificultad es superada cuando la autoridad usa su poder para que la verificación del cumplimiento sea gratuita.

La Circular 1.051 también creó una barrera adicional a la entrada, pues exigió a una eventual AFP entrante informar a todos sus rivales (a las AFP establecidas) el número e identidad de todos los vendedores que desee contratar, con al menos un mes de anticipación. Esto expone al entrante a un bloqueo simple - ofrecer un mejor sueldo a esos vendedores y, si falla, demorar su aprobación- y además lo expone a una respuesta focalizada ${ }^{34}$. Así se crea una asimetría en contra de la AFP entrante y se amplía el menú de herramientas para provocarle daño.

El Cuadro $\mathrm{N}^{\circ} 1$ muestra que la rentabilidad económica sobre activos de las AFP (no del fondo de pensiones) aumentó desde un nivel promedio de $18 \%$ anual entre 1993 y 1997, hasta un nivel promedio de 53\% anual entre 1999 y 2003.

${ }^{33}$ Esa circular ocultó su verdadero impacto presentándose como una descentralización hacia las AFP del listado de vendedores que habían cometido fraude en el pasado. Sin embargo, no hay ganancia social alguna de descentralizarlo y hay enormes costos de hacerlo, como se explica en el texto. Por la misma Circular 1051, la Superintendencia autorizó a las AFP a administrar en conjunto el nivel de dificultad del examen obligatorio de admisión de vendedores, y por tanto el número total de nuevos vendedores autorizados. La industria aprovechó la inédita oportunidad que se le ofrecía y las AFP tomaron en conjunto los exámenes de marzo y junio de 1999.

34 Definimos como "respuesta focalizada" a la práctica de que cada AFP establecida ofrezca un honorario diferenciado a sus vendedores, que sea mayor si el cotizante atraído proviene de la AFP entrante que si proviene de otra AFP establecida. Otra respuesta focalizada que estuvo disponible mientras la Circular $\mathrm{N}^{\circ} 1.051$ estuvo vigente consistía en reprobar a los vendedores de la AFP entrante en el examen de calificación que administraban las AFP establecidas. 


\subsection{Costos del neocorporativismo}

Calificamos como “neocorporativismo” público-privado a la intervención estatal iniciada en 1997-1998 por medio de estas circulares. El neocorporativismo es contrario a los principios de una economía de mercado, aunque ésta no haya sido una consecuencia deseada, como aducen algunos de sus autores. El neocorporativismo hace que las administradoras privadas deban sus utilidades al gobierno y no a la preferencia de sus clientes. Esto deja la posibilidad de que un eventual gobierno irresponsable extorsione a los dueños de las AFP, exigiéndoles favores, como condición para permitirles conservar la renta creada con las circulares descritas. Esos favores podrían afectar a diversas áreas, partiendo con la selección de los directores de las mismas AFP, la votación de las AFP por directores en sociedades anónimas, y la votación de las AFP en las OPA. Otro favor atractivo para un eventual gobierno irresponsable futuro sería conseguir que las AFP destinen parte de los fondos de pensiones a financiar proyectos con un impacto electoral favorable a su reelección, es decir que adopten objetivos “sociales” en la gestión de cartera. Otra posibilidad sería exigir directamente a los dueños de las AFP otorgar gratuitamente algún beneficio a algún segmento del electorado.

En el ámbito de la credibilidad del sistema de AFP y de Chile, que ha exportado este sistema al mundo, el neocorporativismo presenta costos inmensos. Se ha afirmado que el sistema de AFP es privado y competitivo, pero con el neocorporativismo dejó de ser privado y competitivo. El neocorporativismo daña la imagen de la coalición que lo creó.

En cuanto a la eficiencia económica, el neo-corporativismo merece las siguientes críticas:

(1) Algunos de los favores que pueda exigir algún futuro gobierno a las AFP tendrían enormes costos de eficiencia. Es el caso de una reducción de la calidad de los gobiernos corporativos y de la imposición de criterios “sociales” a las decisiones de inversión de los fondos de pensiones.

(2) Una persona requiere de un costoso y largo entrenamiento para convertirse en un asesor previsional de calidad. La especialización de un número importante de personas en esta actividad había sido uno de los éxitos de la nueva seguridad social chilena. Esa especialización implica que la oferta de servicios de vendedores tiene cierta inelasticidad al salario real. En efecto, si alguna AFP redujera el honorario ofrecido a los vendedores en una suma pequeña, por ejemplo \$ 1.000 al mes, la tasa de renuncia no saltaría al $100 \%$, como debería ocurrir si la oferta de servicios de vendedores fuera perfectamente elástica a la remuneración. Por eso, una reducción coordinada de la contratación de vendedores genera aquella pérdida de exce- 
dente social propia de los carteles monopsónicos. Ello también vulnera el derecho de cada vendedor de AFP a emprender una actividad económica legítima, libre de que alguna autoridad se empeñe en que sus eventuales empleadores (las AFP) lo despidan.

(3) La continuación del neocorporativismo puede ser extremadamente costosa. Como es indefendible, se sabe que se adoptará alguna reforma legal para recuperar la competencia. Sin embargo, esto mismo crea una barrera a la entrada que ampara las utilidades sobrenormales. En efecto, para un entrante que intentara formar una AFP nueva en el año 2005, realizando las enormes inversiones comerciales que exige la actual situación comercial y legal, el mayor riesgo es que una eventual reforma que restaure la competencia entre AFP le impida recuperar esas inversiones. Dado ese riesgo, no resulta rentable entrar. Al no haber entrada, las rentas sobrenormales continúan, lo cual mantiene altos los costos de la prolongación del corporativismo.

(4) La superación del neocorporativismo también puede resultar costosa. Cuando se observe un intento serio de legislar para superar el neocorporativismo, cada una de las AFP otorgará una mayor probabilidad al evento de perder una clientela que hoy tiene cautiva. En ese escenario, la estrategia de precios que maximizaría el valor de una AFP para sus dueños sería elevar de inmediato la comisión que aplica a esa clientela cautiva. Esto aumentaría las utilidades sobrenormales de las AFP que siguieran esa estrategia respecto a los niveles actuales, que ya son muy altos. De esta forma, superar el neo-corporativismo puede resultar traumático y conflictivo, afectando el prestigio de la previsión privada.

Existen formas de limitar este posible trauma. El proyecto de ley que recupere la competencia puede imponer sanciones a aquellas AFP que eleven sus comisiones regulares después de aquella fecha en que se inicie la discusión del proyecto. Dos sanciones son: (i) presumir que todos los afiliados de esa AFP solicitan el Servicio de Búsqueda, cualquiera sea el saldo en la cuenta individual, y (ii) impedir a esa AFP y a sus relacionados postular en las licitaciones convocadas por el Servicio de Búsqueda.

(5) El neocorporativismo puede llevar al país a adoptar medidas que empeoren la situación al crear nuevos abusos e ineficiencias, como autorizar la creación de una AFP estatal.

\section{3. ¿Hubo beneficios del neocorporativismo?}

¿Se redimiría la intervención neocorporativista si el gobierno lograra que la rebaja de costos comerciales beneficie a los afiliados, bajando la tasa 
de comisión variable? El Gráfico № 2 muestra que las tasas de comisión netas fueron reducidas por las AFP a partir de 1998. Esto no significa que haya aumentado la competencia entre las AFP. Por el contrario, un acuerdo neocorporativista es el extremo opuesto de la competencia ${ }^{35}$.

Las AFP traspasaron sólo la mitad de la renta creada por el neocorporativismo ${ }^{36}$, siendo que antes de eso ya obtenían una tasa de rentabilidad sobre activos que duplicaba la normal (ver Cuadro $\mathrm{N}^{\circ} 1$ ). Los hechos son los siguientes: al mismo tiempo que las AFP bajaban la tasa de comisión variable, subieron las comisiones fijas. Además dejaron que el aumento en la base de la comisión variable (el salario imponible real) elevara el monto en pesos recaudado por sus comisiones porcentuales, compensando parte de la reducción de tasa. Por último, los regalos a los afiliados traspasados disminuyeron al desaparecer los vendedores. El Gráfico $\mathrm{N}^{\circ} 1$ muestra que en la suma final, las comisiones netas de regalos que pagan los consumidores cayeron cerca de la mitad de lo que cayeron los costos económicos.

Este resultado se explica por las debilidades del neocorporativismo: como es oculto, es también ilegítimo, y eso deja a la autoridad sin poder negociador real para exigir el cumplimiento de la expectativa de una reducción de comisiones. En efecto, es natural que el interés particular de cada AFP la empuje a compartir lo menos posible de la renta obtenida, y eso es factible por la insensibilidad de la demanda a las comisiones. En 1998 y 1999, el superintendente de AFP declaraba por televisión que "ahora les toca a las AFP bajar sus comisiones”, pero las AFP no estuvieron dispuestas a sacrificar la rentabilidad sobre activos de $50 \%$ anual que veían venir.

¿Se redime entonces el neocorporativismo porque hubo una rebaja parcial de la comisión variable, en beneficio de los afiliados? Nuestra respuesta es no. El neocorporativismo es una intervención estatal que ocurre a espaldas de la opinión pública. En ella, el gobierno no informa a los ciudadanos que usa poderes públicos de esta forma, ni que negocia una renta creada por una regulación que él mismo impuso. En el plano de la democracia y de los derechos ciudadanos, el neocorporativismo es inferior a la competencia bajo reglas transparentes. Los demás costos indicados en la sección 5.2 son demasiado grandes.

No creemos que las autoridades que en 1997-2001 adoptaron y luego mantuvieron el neocorporativismo hayan deseado estas consecuencias.

${ }^{35} \mathrm{El}$ aumento de $69 \%$ en el costo de la prima del seguro de invalidez y sobrevivencia entre 1997 y 2003 no fue traspasado a precio (ver nota "Mitos y Realidades" en www.afp-ag.cl). Pero si el mercado de AFP fuera competitivo, debería haber traspasado a precios ese aumento de costo marginal.

${ }^{36} \mathrm{La}$ otra mitad de la renta no llegó toda a los dueños de las AFP, porque también han pagado más impuestos a la renta. 
Esas autoridades habían buscado otras soluciones con ahínco a los problemas causados por los vacíos y fallas identificados en las secciones 2 y 3 , pero no tuvieron éxito en identificar estos vacíos ni en hallar una solución de fondo. En junio de 1997 el gobierno presentó al Congreso un proyecto de ley que derogaba la exigencia de una tasa de comisión única, que era la segunda causa del exceso de gasto en vendedores (como se explicó en la sección 3.4), pero fue rechazado en la Cámara de Diputados. Creemos que ese proyecto tampoco habría resuelto el problema, pues no daba una respuesta adecuada a la baja sensibilidad de los afiliados a las diferencias de comisión ni a la demanda social por equidad en las comisiones.

También debe recordarse que las AFP no son responsables del marco regulatorio que les dio el gobierno. Creemos que hasta 2001 Chile pagó uno de los costos de ser un líder mundial en materia previsional: Chile no ha podido copiar soluciones para estos problemas, porque son nuevos.

Así, fue una decisión sabia aquella que en noviembre de 2001, después de cuatro años, llevó a la Superintendencia de AFP a dictar la Circular 1.176, que derogó la infausta Circular $1.051^{37}$. Sin embargo, la evidencia en los gráficos y en el Cuadro $\mathrm{N}^{\circ} 1$ demuestra que algunos efectos del neocorporativismo persistían en 2003. Las cifras para 2004 y el primer trimestre de 2005 lo confirman. Las AFP continúan coordinándose en no contratar vendedores. Ponen comisiones en un nivel que permite cosechar las utilidades del neocorporativismo pero no permiten a un eventual entrante financiar una entrada tradicional con cientos de vendedores. Sin embargo, las utilidades de las AFP siguen siendo vulnerables a las actuaciones y exigencias de alguna autoridad irresponsable futura. Por ello, no es aceptable tolerar un cartel monopsónico, pues los afiliados y ciudadanos quedan expuestos a futuros acuerdos a sus espaldas.

\subsection{Entrada de los bancos a la industria de AFP}

El sobreprecio de 80 millones de dólares al año ha alentado la creación de una coalición para permitir que los bancos creen filiales AFP. Desde un punto de los derechos, ésta sería una medida equitativa, pues la prohibición que hoy afecta a los bancos de propiedad diluida chilena es una limitación objetiva a sus oportunidades de negocio, que no sufren otros distribuidores masivos como las tiendas de departamento, los supermercados y los bancos de propiedad de consorcios internacionales.

${ }^{37}$ La Circular 1.176 entró en vigencia a partir del 1 de octubre de 2001. 
No es válida la objeción de que eventuales AFP filiales de bancos podrían manipular los precios de los títulos para extraer recursos a los afiliados. Un ejemplo de esa manipulación, que se ofrece entre murmullos, es que un banco enfrentado a alguna empresa deudora con problemas de pago podría hacer que ella emitiera bonos, que serían comprados por la AFP filial a precios que no reflejarían el riesgo del emisor, y luego haría que esa empresa destinara esos recursos a pagar el crédito al banco. Esta manipulación no es posible debido a las numerosas medidas cautelares contenidas en la Ley de Valores y el D.L. 3.500. El absurdo es evidente, pues si esta manipulación fuera factible, entonces ya sería de uso masivo por parte de las grandes AFP cuyos dueños poseen también bancos en Chile.

Sin embargo, la entrada de los bancos no hace nada por resolver los problemas identificados en las secciones 2 y 3 . El Estado continuaría actuando en forma asimétrica, forzando a los trabajadores a comprar servicios de AFP pero negándoles ayuda institucional efectiva para comparar comisiones. Esto causa que la baja sensibilidad de los afiliados a las diferencias de comisión, que hace el negocio de AFP tan atractivo para los bancos, no sería resuelto. El Estado también continuaría satisfaciendo la demanda social por comisiones equitativas de manera ineficiente, por medio de aquella regulación que impone una tasa de comisión única en función del salario a cada AFP por separado. Para los bancos de nicho, ésta sería una oportunidad dorada para establecer AFP especializadas en cotizantes de alto salario. En materia de la concentración de la gestión financiera, la aparición de AFP filiales de bancos podría aumentar la concentración medida a nivel global.

La entrada de los bancos puede empeorar el escenario que llevó al neocorporativismo: Banco del Estado creará una filial AFP. Su prestigio en amplios sectores y su potente red comercial permitirían a una AFP Banco del Estado acercarse a la situación uruguaya, donde AFAP República (estatal) gestiona el 56\% de los fondos de pensiones. Su potencia comercial se explica porque mucha gente de ingresos medios la preferiría por razones políticas.

Una AFP estatal tampoco resolvería los problemas identificados en las secciones 2 y 3. La hipótesis de que una AFP estatal permitiría regular las comisiones a la baja es contradicha por la experiencia de Argentina (desde 1994) y Uruguay (desde 1997), donde la AFP estatal no es más barata. Es efectivo que una AFP de propiedad estatal aliviaría la insensibilidad a las comisiones si bajara las suyas lo suficiente para incentivar a muchos afiliados a considerar que la diferencia de precio justifica invertir en informarse. Sin embargo, eso requeriría que la AFP estatal bajara su comisión muy por debajo de las privadas (que es 2,3\% en promedio), quizá al menos hasta 1,3\%. El problema es que si una AFP estatal bajara la comisión 
a 1,3\% del salario, no cubriría sus costos. Así, la única manera de que una AFP estatal pueda hacer una diferencia respecto a la gran masa de afiliados es con competencia desleal, lo que sería un delito contra la libre competencia. Pocos actores privados querrían entrar a formar una AFP en este escenario, y algunas preferirían vender su negocio a la AFP estatal.

Una AFP estatal también crearía interferencia política. Su votación en las juntas de accionistas de aquellas cien sociedades chilenas donde los fondos de pensiones mantienen acciones, se politizaría en manos de algún gobierno irresponsable. Si bien por sí misma no podría elegir directores en ninguna empresa, la AFP estatal podría acordar convenios con otras AFP para apoyar a sus candidatos respectivos en las elecciones de directores en distintas empresas, o para coordinar las votaciones en las Ofertas Públicas de Acciones (OPA). Con estas maniobras, un oficialismo irresponsable podría acceder a estupendos puestos de directores, donde a su vez podrían influir para que las empresas financiaran a los candidatos oficialistas en la siguiente campaña electoral. La AFP estatal también podría liderar la adopción de criterios de inversión "social”, cuyo objetivo real puede ser lograr un impacto electoral.

Si el fondo de pensiones de la AFP estatal fuera grande en relación con los demás, arrastraría a las otras AFP a copiar su cartera, al menos parcialmente. Eso permitiría a un gobierno irresponsable, que controlaría Banco del Estado y a su AFP filial, influir sobre el costo de fondos de las empresas.

Algunos dudan de que una AFP estatal pueda alcanzar un tamaño significativo, aduciendo que hacer crecer esa AFP exigiría fuertes aportes de capital para financiar el Encaje. En efecto, una AFP que gestione el 30\% del fondo de pensiones requeriría un Encaje cercano a 165 millones de dólares. Esta duda no convence, porque el Banco del Estado no necesita aportar recursos para financiar el Encaje de su filial. La propia AFP puede financiarlo emitiendo bonos, posiblemente indizados al valor del Encaje. En todo caso, ese monto de Encaje era una cifra cercana al 25\% del patrimonio neto del Banco del Estado a fines de 2004, por lo que sería financiable en unos pocos años, sin pedir aportes de capital al Ministerio de Hacienda.

Una respuesta frente a estos problemas es que la ley exija una conformación especial del directorio de esa AFP estatal, que minimice el cuoteo político dando garantías de calidad técnica. También se podría exigir que los procedimientos de esa AFP estatal para votar en juntas de accionistas y en las OPA incluyan un blindaje adicional contra el cuoteo político. Sin embargo, esto no convence del todo porque un directorio designado por la coalición de gobierno igualmente podría interferir en la forma indicada, cualesquiera sean los títulos técnicos de sus integrantes. Sin restricciones efec- 
tivas para la politización de la AFP Banco del Estado, la mera entrada de bancos podría empeorar la situación respecto al neocorporativismo. En cambio una solución como la propuesta en este trabajo, combinada con restricciones especiales a la AFP Banco del Estado, eliminaría las objeciones para autorizar a los bancos a tener filiales AFP.

\section{Propuesta de reforma}

Las siguientes medidas, como se señaló en la Introducción, son un paquete unitario, cuyo éxito depende de una aplicación conjunta:

(a) Exigir a cada AFP actual desdoblarse en una AFP "pura”, cuyas únicas funciones serían la gestión financiera y el contacto con los afiliados, y un "operador básico" que cumpla las demás funciones.

(b) Crear un canal institucional nuevo para que las AFP "puras" capten afiliados, que cubra a un número sustancial pero nunca a todos los afiliados. Este nuevo canal sería un Servicio de Búsqueda de la AFP más barata, creado expresamente. La propuesta se traduciría en una buena gestión financiera.

(c) Satisfacer la demanda social por comisiones equitativas mediante una única tasa de comisión aplicada a los clientes de todos los "operadores básicos”. Respecto a las AFP "puras”, esa demanda se satisfaría sólo para quienes usen el servicio de búsqueda de la AFP más barata.

La sección 2.4 explicó los elementos centrales del Servicio de Búsqueda de la AFP más barata. Esta sección describe las otras dos medidas y precisa elementos adicionales que debe tener el Servicio de Búsqueda para que el paquete unitario sea efectivo.

\subsection{Desdoblar actuales AFP en AFP "puras” y “operadores básicos”}

Es deseable que la concentración sea alta en la operación básica, pero la concentración es un problema respecto de la gestión financiera. El desdoble permite que la gestión financiera se desconcentre, y a la vez que las economías de escala en la operación básica sean aprovechadas en mayor medida. Esta medida ha sido discutida largamente en círculos de expertos y cuenta con un amplio apoyo, nacional e internacional.

En concreto, se define que un "operador básico" es cualquier empresa que desarrolla las labores reservadas en la ley a los operadores básicos para el servicio del ahorro obligatorio. Las funciones reservadas por ley son las operativas (recaudación de cotizaciones, pago de pensiones, determina- 
ción de beneficios, atención de público en sucursales —hay unas 600 mil visitas a sucursales al año) y la prestación del seguro de invalidez y sobrevivencia- Los operadores básicos tendrían prohibición de prestar servicios de gestión financiera a cualquier cliente, sea por ahorro voluntario o forzoso.

La dispersión de la gestión financiera no puede lograrse permitiendo a las actuales AFP subcontratar a terceras empresas especializadas en aquellas funciones que tengan economías de escala, como muestra la experiencia chilena, que ha intentado esa vía durante dos décadas. En efecto, la formación del precio del servicio subcontratado enfrenta a cada una de las AFP con un especialista que es dominante gracias a las economías de escala. El precio que cada AFP obtiene depende de su tamaño, pues éste permite a las AFP más grandes ejercer un poder monopsónico que se traduce en fuertes descuentos por volumen. En definitiva, las AFP más grandes internalizan parte de la economía de escala del especialista, pero las AFP más pequeñas no lo hacen. Esta situación incentiva a las AFP a fusionarse para acceder a descuentos mayores de parte del especialista. El resultado de la subcontratación es que los niveles de costo caen, las comisiones caen menos que los $\operatorname{costos}^{38}$, y la gestión financiera queda tan concentrada como si cada AFP realizara su función operativa en forma aislada.

Conviene mencionar por qué descartamos la alternativa de que las AFP formen una "cooperativa" que les preste los servicios operativos, al estilo del DCV y del Operador del Subsidio de Cesantía. Pareciera que una cooperativa tiene la ventaja de evitar que la autoridad fije tarifas, pero ello es ilusorio, porque es esencial que la autoridad intervenga de al menos dos maneras: (i) debe impedir que la cooperativa actúe como un cartel, cobrando a sus socios tarifas muy superiores a sus costos, para luego distribuir las utilidades a las AFP miembros. Impedir esto exige fijar las tarifas de la cooperativa $^{39}$; (ii) debe impedir que la cooperativa cree barreras a la entrada a la industria de AFP "puras". Esto podría ocurrir si la cooperativa eleva suficientemente el precio de nuevas acciones que emita a AFP entrantes, o las tarifas cobradas a los clientes no socios. También ocurriría si la cooperativa utiliza su base de datos para informar a las AFP establecidas la identidad y empleador de los afiliados que eligieron a la AFP entrante, para que las AFP establecidas puedan dirigir sus vendedores a esos afiliados y ofrecerles regalos, elevando la tasa de rotación de la AFP entrante a niveles que la obliguen a salir del mercado. Para impedir esto, el Estado tendría que fijar el

${ }^{38}$ Porque el especialista y las AFP grandes capturas alguna renta sobrenormal.

39 Éste podría ser un problema grave con el Operador del Seguro de Cesantía a partir de 2011, cuando venza el plazo inicial de diez años para el cual una licitación fijó las tarifas. Éste también podría ser un problema con el DCV, que parece obtener rentabilidades sobrenormales, ajustadas por riesgo. 
precio de las acciones que emita, vigilar las fórmulas tarifarias que aplique la cooperativa para asegurarse de que ellas no discriminen contra las AFP entrantes, y exigir confidencialidad de las bases de datos (esto último es poco creíble).

El desdoble, para ser efectivo, debe ir acompañado de una redefinición legal de las relaciones comerciales. Si el afiliado contratara a alguna AFP "pura” y ésta fuera quien contrata a uno o más operadores básicos, habría una permanente negociación de tarifas entre AFP "puras” y “operadores básicos”. Esa renegociación replicaría las actuales negociaciones con los especialistas, que conducen a mantener la actual concentración de la gestión financiera. Para evitar esto, se propone prohibir por ley que una AFP "pura” contrate a un operador básico para prestar servicios a sus clientes forzosos. En cambio, las funciones operativas relacionadas con servicios voluntarios, como Ahorro Previsional Voluntario (APV) y fondo mutuo (CAV) podrían prestarlas los operadores básicos, pero sin una reserva especial en su favor, así que otros también podrían prestarlas. La próxima sección indica cómo se contrataría a los operadores básicos.

\subsection{Comprador Central de Servicios Previsionales}

En la sección 6.3 se propone una medida para satisfacer la demanda social por comisiones equitativas a nivel de las AFP "puras". En esta sección discutimos la forma de satisfacer esa misma demanda respecto a los “operadores básicos”.

La ley indicaría que si el Tribunal de la Competencia establece que alguna de estas empresas operativas tiene una posición dominante, deberá sujetarse a fijación de tarifas y a obligaciones de prestar servicio. Por eso, la propuesta debe considerar dos escenarios, según si el Tribunal de la Competencia declare que hay un operador básico dominante a nivel nacional, en cuyo caso sus tarifas serían fijadas. El otro escenario incluye una variedad de situaciones. Lo principal es que en las regiones donde el Tribunal reconozca que no hay un operador dominante, que podrían ser todas, coexistan varios "operadores básicos" con tarifas libres.

Consideremos este último escenario, donde coexistan unos pocos “operadores básicos” rivales. Algunos operadores básicos se especializarían en prestar ciertos servicios, como las aseguradoras que den el seguro de invalidez y sobrevivencia, y otros prestarían varios servicios en conjunto para aprovechar economías de ámbito.

Proponemos resolver la demanda social por comisiones equitativas reservando por ley la facultad de comprar los servicios de los operadores 
básicos, por cuenta de los afiliados con ahorros forzosos, a un ente que llamaremos "Comprador Central de Servicios Previsionales" (CCSP), integrado por una mayoría de representantes de los directorios de todas las AFP "puras" y por una minoría de ingenieros expertos en tecnologías de la información (IT), sujetos a fuertes incompatibilidades ${ }^{40}$. El CCSP tendría funciones asignadas por ley, que incluirían diseñar los contratos de servicio de los operadores básicos, que tendrían varios años de duración, y asignarlos por medio de licitaciones ${ }^{41}$. La ley responsabilizaría a los directores del CCSP de lograr las mejores combinaciones de comisión y calidad de servicio, y los sujetaría a la fiscalización y evaluación de la Superintendencia de AFP. Este nuevo ente sigue el modelo de la Comisión Clasificadora de Riesgo de las AFP, que ha funcionado con un esquema similar. La existencia de un único comprador (el CCSP) hace innecesario fijar tarifas a los operadores básicos que sean dominantes en alguna región.

Por otro lado, la ley autorizaría al CCSP a establecer una comisión de tasa única aplicada a todos los salarios imponibles de los cotizantes a las AFP, cuya recaudación financiaría la compra de servicios a los operadores básicos. La tasa de esta comisión sería ajustada todos los semestres en función de los cobros efectivos realizados por los operadores básicos conforme a contrato, con una fórmula del tipo:

(1) tasa comisión $_{\text {perídot }}=\frac{\sum_{i} \text { Cobro Operador Básico }_{i, \text { perído t-1 }}}{\sum_{k} \text { Salario Imponible Cotizante }_{k, \text { perído } t-1}}$

El contrato de cada operador básico lo autorizaría a cobrar una comisión preliminar a los cotizantes, a la tasa establecida en (1). De existir un exceso sobre el cobro convenido, el contrato lo obligaría a transferirlo de inmediato al CCSP, quien a su vez lo pagaría de inmediato a los operadores básicos con pagos incompletos. La Ley también autorizaría al CCSP a cobrar una tasa hasta $10 \%$ mayor que (1), con el objeto de construir y mantener una reserva para enfrentar fluctuaciones.

${ }^{40}$ Los puestos en el directorio del CCSP deberían ser incompatibles con relaciones de control de operadores básicos (por ejemplo, si una AFP "pura” está coligada con un operador básico, la primera no podría designar a un miembro de su directorio en el CCSP), con relaciones de propiedad y control de empresas que presten servicios a operadores básicos (asesorías de tecnologías de información y en gestión de operaciones), y con puestos pasados o futuros en el gobierno, en el Congreso y en partidos políticos.

${ }^{41}$ Debe descartarse la idea de fijar la tasa de la comisión sobre la base de precios negociados entre una AFP “pura” individual y un operador básico. Eso permitiría que el precio negociado fuera manipulado, es decir aumentado, con el objeto de elevar la tasa de impuesto aplicada a los cotizantes. 
Este escenario es compatible con que los operadores básicos registren importantes economías de escala. La coexistencia de varios operadores básicos será posible cuando los ahorros de costos que generaría una eventual fusión sean estimados de valor inferior a las ventajas que aprecia el CCSP de contar con proveedores diferentes. Por ejemplo, si hubiera un operador básico dominante en cada grupo de regiones, el CCSP ganaría información al comparar los precios obtenidos en las distintas regiones. Además, el CCSP alentaría la competencia entre proveedores por medio de innovaciones.

Debido a la multiplicidad de operadores con diversas tecnologías, la función de licitación de servicios que realizaría el CCSP en este escenario sería un poco más sofisticada que la licitación convocada en 2001 por el Ministerio del Trabajo para proveer el servicio de operador del Seguro de Cesantía. Sin embargo, al final la complejidad se limita a especificar claramente los estándares de servicio exigidos y la confiabilidad y respaldo, antes de escoger el ganador, dejando que los postores privados resuelvan los problemas tecnológicos.

En la solución propuesta, cada operador básico podría prestar servicios a otros clientes (privados) también. Esto permitiría participar en las licitaciones a proveedores especialistas del sector privado, como bancos y Servipag. También se podrían integrar operaciones con otras ramas de la seguridad social (operador del seguro de cesantía, las Isapre) y con el Servicio de Impuestos Internos. Es de suponer que entidades como Previred continuarían prestando servicios.

Conviene precisar también qué significa esta propuesta para el seguro de invalidez y sobrevivencia. La prima de este seguro seguirían pagándola los cotizantes, como en la actualidad, pero a través del impuesto propuesto. Las aseguradoras básicas tendrían la obligación de reasegurarse para cubrir siniestralidades catastróficas de los afiliados a su cargo, tal como ocurre con las AFP actuales. Ellas tendrían la posibilidad de cuestionar solicitudes de invalidez y declaraciones de defunción, con el fin de limitar el fraude y el peligro de abuso de parte de los afiliados. Las comisiones médicas serían financiadas en parte por las aseguradoras básicas, tal como ocurre hoy.

La principal ganancia es que las diferencias predecibles de siniestralidad (por salario, edad, sexo, región y ocupación) no originarían rentas a las AFP que gocen de una clientela con siniestralidad inferior al promedio, como ocurre en la actualidad. En efecto, la ley vigente prohíbe a una AFP traspasar la menor siniestralidad predecible a un cliente con una menor tasa de comisión. Las diferencias predecibles de siniestralidad incentivan a las 
AFP a competir entre sí invirtiendo en captar a los clientes de menor siniestralidad, llegándose incluso a pagar honorarios diferenciados a los vendedores según la edad y sexo de los afiliados que traspasen. Otra forma de competencia que desaparecería es el regalo de más servicios a los cotizantes de menor siniestralidad (mantención diferenciada). Estas inversiones comerciales elevan los costos, y como además parte de ellos son fijos, refuerzan la actual tendencia a la concentración. Estos efectos desaparecerían.

Creemos posible una ola de fusiones entre operadores básicos para competir de mejor forma en las licitaciones organizadas por el CCSP. A diferencia de la situación actual, los ahorros logrados serían transferidos a los cotizantes. No contamos con información para estimar la magnitud de estos ahorros, pero comparaciones simples con los costos logrados en Suecia por el sistema PPM sugieren que podrían ser sustanciales, hasta $0,32 \%$ del salario imponible (Palmer, 2004) ${ }^{42}$. De ahorrarse en la cuenta individual, esta suma podría elevar la pensión en $3 \%$.

La base del impuesto propuesto es la masa salarial y no el fondo de pensiones. Ello se justifica por dos razones: (i) aplicar el impuesto al fondo sería más gravoso para los afiliados de mayor edad, porque el saldo de la cuenta individual crece con la edad, ceteris paribus. Como hasta ahora los costos operativos han sido pagados con comisiones proporcionales al salario, esos afiliados ya han pagado su parte de esos costos cuando estuvieron activos, en el entendido de que no se les cobraría cuando ya estén pasivos. Un cambio de base implicaría cobrarles de nuevo cuando estén

42 Palmer reporta los siguientes costos del sistema PPM para 2005: 40 millones de coronas por recaudación, más 352 millones de coronas por operaciones (actualización de 6 millones de cuentas individuales, envío de información impresa a los 6 millones de afiliados, entrega de información en call center y sitio web, desarrollo interno de sistema IT, transacciones diarias con 650 gestores de fondos, costos de administración general, pago parcial del costo de la información individualizada de cotizaciones, y pago parcial de la red de sucursales de la seguridad social, que también recibe consultas y realiza trámites para los afiliados del sistema PPM). Al tipo de cambio de 0,141 dólares por cada corona sueca, esto hace un total de 55 millones de dólares al año. Para lograr una estimación conservadora, olvidaremos que la mano de obra es más barata en Chile que en Suecia y usaremos el tipo de cambio de mercado, \$ 600 por dólar, resultando un costo de Ch \$33.000 millones al año (lo que es muy superior al costo de Ch $\$ 2.760$ millones que registró la Administradora de Fondos de Cesantía en 2004). Esto equivale a Ch $\$ 808$ por cotizante al mes, es decir $0,27 \%$ del salario promedio. Sumando una prima de seguro por $1,00 \%$ del salario imponible, resulta que el costo de un operador básico que explote todas las economías de escala sería cercano a 1,27\% del salario. Sumando el costo de la AFP "pura" que gestiona los fondos por aproximadamente $0,21 \%$ (ver sección 3.2), la comisión total sería 1,48\% del salario incluyendo seguro. Comparando con la actual comisión de $2,30 \%$ del salario, pero sin considerar la utilidad sobrenormal de $0,50 \%$ porque ella es transferida por el Servicio de Búsqueda, resulta un potencial ahorro de costos de $1,80 \%-1,48 \%=0,32 \%$ del salario, atribuible a una mejor organización de las operaciones. 
pasivos, causando una redistribución no deseada, y (ii) la prima del seguro es proporcional a las indemnizaciones por siniestros, que a su vez varían directamente con los salarios imponibles, no con el fondo de pensiones.

En el escenario opuesto, el Tribunal de la Competencia dictamina que existe un operador básico dominante. El CCSP sólo podría negociar bilateralmente frente a tal monopolio, lo que sería ineficiente. Por eso la propuesta es, para este escenario, fijar tarifas al monopolio con un proceso de tarificación establecido por ley, que ofrezca garantías a cualquier eventual dueño del operador único. La Superintendencia sería dotada de poderes fiscalizadores respecto de ese eventual monopolio, controlaría los estándares de calidad de servicio (como ha hecho desde 1981). La demanda social por comisiones equitativas se resuelve en este escenario de otro modo: estableciendo que la tarifa sea una tasa única aplicada al salario imponible de los cotizantes.

Si bien esto implica discriminar en precios entre afiliados, no atraería las prácticas y estrategias descritas en la sección 3.4 porque en este escenario hay un único operador básico. Los costos tampoco pueden subir por la vía de que entren operadores básicos en pequeña escala para aprovechar subsidios cruzados. El operador único tampoco invertiría en sobornos a las AFP con mayor salario imponible promedio, porque esa AFP no tendría proveedor alternativo.

El esquema global propuesto, con dos escenarios legislados desde el principio, toma en cuenta que el avance tecnológico podría dejar obsoletas algunas funciones de costo observadas en el pasado. Si nuevas tecnologías hacen posible que nuevos oferentes repliquen los bajos costos de los actuales operadores, habrán desaparecido las economías de escala observadas en el pasado. En respuesta, el sistema pasaría desde el escenario de empresa dominante tarificada al de múltiples oferentes contratados por el CCSP.

\subsection{Otros elementos del Servicio de Búsqueda}

La sección 2.4 presentó los elementos centrales del Servicio de Búsqueda de la AFP más barata que se propone. Las secciones siguientes mostraron por qué también es necesario cumplir otros objetivos, relativos a equidad y a desconcentración de la gestión financiera. Esta sección indica cómo podría estructurarse el Servicio de Búsqueda para cumplir estos otros objetivos.

a) Demanda por equidad en las comisiones. Con el fin de satisfacer esa demanda respecto a las AFP “puras”, el Servicio de Búsqueda exigiría 
que la postura fuera una tasa de comisión única, expresada como porcentaje del salario imponible de los cotizantes que integren el bloque asignado ${ }^{43}$. Para que la tasa de comisión ganadora sea similar entre bloques, se requiere que el ingreso de servir los distintos bloques sea similar. Eso puede lograrse si la Comisión Supervisora del Servicio de Búsqueda distribuye aleatoriamente la masa salarial imponible de todos los cotizantes beneficiados, entre los distintos bloques. La necesidad de cumplir esta función exige que la Comisión Supervisora sea única.

b) Protección contra descreme por AFP rivales. La postura de una AFP en la licitación depende en parte de la expectativa respecto a la permanencia del bloque de usuarios. Esa permanencia será alta si es el afiliado quien debe tomar la iniciativa para irse de la AFP asignada. Sin embargo, falta considerar el incentivo de una AFP rival para atraer afiliados que recibieron el Servicio de Búsqueda, específicamente cotizantes jóvenes de alto salario y bajo saldo, que dejan un alto margen por causa de la propuesta (a), que satisface la demanda social por comisiones equitativas. La AFP rival puede convencerlos aunque su comisión regular sea mayor que las logradas por el Servicio de Búsqueda, si además ofrece un premio de entrada, pues esa combinación equivale a un crédito de consumo ${ }^{44}$. Ese premio de entrada no sería observable para la Superintendencia si es otorgado vía vendedor. Para que el Servicio de Búsqueda logre comisiones equitativas, proponemos medidas que reduzcan la permanencia del nuevo afiliado para la AFP rival. La primera es publicar el nombre, el salario imponible, la dirección del empleador y el domicilio de todos aquellos afiliados que reciban el Servicio de Búsqueda y se cambien a otra AFP. La segunda es prohibir que la AFP que reciba primero a este afiliado pueda comprometer la permanencia de éste con ningún tipo de contrato ${ }^{45}$.

c) Requisitos para postular y barreras a la entrada. Los requisitos de experiencia son útiles, pero para evitar que se conviertan en barreras a la entrada deben ser diferentes entre AFP nuevas y antiguas. Para las AFP antiguas, un posible requisito sería que haya sido elegida por un mínimo de

${ }^{43}$ La comisión fija no sería necesaria.

${ }^{44}$ Una barrera natural es que la diferencia de comisión regular debe financiar el costo del contacto individual. Sin embargo este costo puede ser menor que el $0,26 \%$ del salario estimado en la sección 2 para vendedores de productividad promedio, porque el cotizante en cuestión puede ser un antiguo cliente de la AFP rival, ya identificado a cero costo.

${ }^{45}$ Una tercera sería exigir que la AFP a la cual llega el afiliado pague una multa a la AFP que ganó la licitación, de monto igual al salario imponible multiplicado por la tasa de comisión licitada, y por el número de meses que falta para el siguiente llamado a licitación. No es posible limitar la comisión de la AFP a la cual llega el afiliado, porque ello equivaldría a prohibir al afiliado cambiarse a AFP más caras que el límite, contradiciendo el carácter no vinculante del Servicio de Búsqueda. 
diez mil afiliados y que haya contado con un mínimo de 5 mil cotizantes, sin ayuda del Servicio de Búsqueda. Para las AFP formadas hace menos de un año (nuevas), un posible requisito para postular sería que sus socios hayan administrado APV, seguros de vida con ahorro o fondos mutuos para un mínimo de cinco mil clientes. La Comisión Supervisora del Servicio de Búsqueda precisaría estos requisitos.

d) Desconcentración de la gestión financiera global. Se desea evitar que el Servicio de Búsqueda concentre la gestión financiera a nivel del conjunto de los intermediarios financieros chilenos, incluyendo AFP, bancos, fondos mutuos, fondos de inversión y compañías de seguros de vida, pues esa concentración puede afectar al costo de fondos de las empresas. Con el fin de garantizar esta meta, se propone que una misma AFP postora no pueda ser asignataria de un número de cuentas tal que, al sumar sus saldos a los demás activos financieros chilenos que administra el grupo empresarial controlador, supere el $15 \%$ del total de todos los activos de los intermediarios financieros chilenos. El contrato de concesión prevería que, en caso de que los controladores de una AFP asignataria se fusionen y superen el límite de $15 \%$, se adelantaría el término de las concesiones y se llamaría a una licitación extraordinaria.

e) Desconcentración de la gestión financiera de Fondos de Pensiones. La banda de rentabilidad relativa hace un gran aporte a la calidad de la gestión financiera de los fondos de pensiones (ver sección 6.4). Sin embargo, esa banda fracasaría si la concentración en el sistema de AFP, evaluada por sí sola, resulta muy alta por efecto del Servicio de Búsqueda. Para evitar que esto ocurra, se propone exigir que una misma AFP postora, o grupo de AFP postores relacionados, no pueda ser asignataria de más de dos bloques de 500 mil afiliados ${ }^{46}$.

f) Considerando la naturaleza de las funciones propuestas, es importante que los miembros de la Comisión Supervisora estén libres de conflictos de intereses. A modo ilustrativo, se propone que el Banco Central de Chile (autónomo) llame a un concurso público para elegir una lista de doce expertos financieros que no hayan tenido actividad partidista, ni hayan tenido contratos con AFP postulantes potenciales y sus empresas relacionadas en los últimos dos años. Dentro de esa lista el Senado podría elegir dos a propuesta del Presidente de la República, los decanos de las cinco facultades de Derecho y Economía con más publicaciones científicas podrían elegir a otros dos, y el Tribunal de la Competencia podría elegir al quinto. La

${ }^{46}$ Para estos efectos, la Comisión Supervisora tendría que definir cuándo dos AFP son distintas. Una posible definición es que son distintas si los grupos controladores de cada una difieren en al menos el $30 \%$ de la propiedad. 
Superintendencia de AFP no debe actuar como secretaría técnica de esta Comisión Supervisora, ya que eso le impediría fiscalizarla.

\subsection{Incentivos a una buena gestión financiera}

El retorno financiero tiene una influencia sobre el monto de las pensiones que rivaliza con la influencia de la densidad de cotizaciones. El retorno esperado depende en primer lugar del riesgo asumido por los afiliados, y en segundo lugar de los límites de inversión. La calidad de la gestión financiera prestada por AFP particulares tiene una magnitud mucho menor, en el entendido de que cumple con estándares aceptables, como aquellos impuestos por la banda de rentabilidad relativa. Esta sección revisa los efectos del Servicio de Búsqueda sobre la gestión financiera. Ellos resultan ser tres: incentivos para ahorrar en calidad de gestión, incentivos a sustituir comisión propia por las comisiones de gestores delegados, e incentivos monetarios para mejorar el desempeño financiero.

1. Incentivos para ahorrar en calidad de gestión. Como el Servicio de Búsqueda prefiere a las AFP que proponen menor comisión, deja de lado el tema de la gestión financiera. Esta ausencia se debe a que la Comisión Supervisora no podrá contar con técnicas de bajo margen de error para predecir las diferencias futuras de desempeño financiero entre cualquier par de AFP a tres años plazo, porque ellas no existen. Sin embargo, una licitación que omita considerar la calidad de gestión podría incentivar para que los postores ahorren en gestión financiera. Hay dos razones para estimar que ello no ocurrirá:

a) La norma de "rentabilidad mínima (relativa)" obliga a cada AFP a sujetar a cada uno de sus multifondos a un desempeño de referencia, que es el promedio de los retornos de los multifondos rivales. Para minimizar el riesgo de perforar el piso de la banda, el directorio de la AFP exige todos los meses explicaciones para las diferencias de desempeño financiero respecto a los demás multifondos de la misma clase. Esta dura comparación entre expertos, evaluada por otros expertos, impide que cualquier multifondo en particular se despreocupe de la gestión financiera, con una condición: que al menos alguna AFP esté dispuesta a invertir para brindar una buena gestión $^{47}$.

${ }^{47}$ En el caso de aquellas AFP que definen cada uno de sus multifondos como una combinación en diferente proporción de una misma cartera de renta variable y una misma cartera de renta fija, hay un efecto adicional: cuando esa AFP logra un mejor 
A su vez, habrá algunas AFP dispuestas a invertir para lograrla, en la medida en que los afiliados de alto ingreso premien con traspasos netos favorables a las AFP que brinden mejor gestión financiera. La evidencia indica que el afiliado de alto ingreso tiene un interés mayor y cuenta con mayor información y capacidad para estimar las diferencias esperadas de desempeño financiero ${ }^{48}$. Debido a esto, la banda de rentabilidad relativa es capaz de forzar a todas las demás AFP a invertir también en gestión financiera, incluso a aquellas que obtengan todos sus clientes a través del Servicio de Búsqueda.

b) Es probable que varias de las AFP que ganen las licitaciones del Servicio de Búsqueda aspiren además a contactar clientes de alto ingreso o alto saldo. Para servir a estos segmentos, cada AFP deberá hacerlo a través de los mismos multifondos que atienden a los clientes intermediados por el Servicio de Búsqueda. Luego, si esa AFP desea entregar a clientes de alto ingreso una buena gestión financiera, tendrá que entregarla también a los afiliados que recibieron servicios de búsqueda.

Para que ambos mecanismos — que son los que existen hoy- operen con toda su fuerza, bastaría con que cada clase de multifondos (clase A, B, C, D o E) administre en conjunto suficientes recursos de clientes de alto ingreso. Como existe una fuerte correlación positiva entre salario imponible y saldo de la cuenta individual, bastaría con que en cada clase de multifondo la proporción de los fondos totales de propiedad de afiliados no beneficiados por el Servicio de Búsqueda sea suficiente. ¿Qué es suficiente? En un contexto donde la concentración de la gestión financiera es inferior a la actual, si 30\% de los fondos de cada tipo fuera de propiedad de afiliados de alto saldo, habría al menos tres AFP compitiendo por prestarles servicio. Esto sería suficiente. Se deduce que podemos estar tranquilos si el porcentaje de los fondos totales de propiedad de afiliados beneficiados por el Servicio de Búsqueda es inferior a 70\%.

desempeño en cualquiera de esas carteras beneficia a todos sus multifondos a la vez. Se deduce que basta con que al menos alguna AFP esté dispuesta a invertir en una buena gestión financiera de renta fija, para obligar a todas las AFP que definan sus multifondos de esta forma a invertir en la gestión de renta fija. Lo mismo vale para la cartera de renta variable.

${ }^{48}$ Valdés y Marinovic (2003, Cuadros VII.3 y VII.4), encuentran que los cotizantes de AFP Cuprum, que tienen el mayor ingreso promedio, son sensibles a las diferencias de desempeño financiero, lo que no ocurre con los demás cotizantes. Según la regresión logit ordenada reportada por Berstein y Ruiz (2005, Cuadro $\mathrm{N}^{\circ} 1$ ). Comparando afiliados de ingreso tope (60 UF) con los de ingreso medio, la probabilidad de tener un grado alto de conocimiento previsional es 26,1 puntos porcentuales mayor para los de mayor ingreso, mientras que la probabilidad de tener un grado bajo de conocimiento previsional es 17,8 puntos porcentuales mayor para los de ingreso medio. 
Para lograr esa meta se proponen dos medidas:

(i) La Comisión Supervisora definiría los bloques de usuarios del Servicio de Búsqueda de forma que cada uno incluya proporciones similares de usuarios en los distintos multifondos. Esto asegura que un mal desempeño en renta fija, por ejemplo, moleste a los clientes de los cinco multifondos, incluyendo a los clientes de alto ingreso, cualquiera sea el multifondo que hayan preferido.

(ii) Fijar el umbral para el saldo que gatilla la presunción de solicitar el Servicio de Búsqueda, con una fórmula del tipo (ésta es una ilustración): para cada afiliado, el umbral sería el menor entre:

(a) el precio de una pensión mínima (\$ 10 millones). El efecto de este requisito por sí solo fue reportado en la sección 2.4 , y es que el 38,3\% del fondo recibe Servicio de Búsqueda,

(b) aquel monto que deja un máximo de $70 \%$ de los fondos totales de la clase de multifondo en la cual está el afiliado, en cuentas acogidas al Servicio de Búsqueda. Este monto varía según el multifondo del afiliado. Por ejemplo, si hay relativamente pocos afiliados de saldo alto entre los que están en el multifondo E, entonces esto excluye a más afiliados que están en el multifondo E de la presunción de solicitar el Servicio de Búsqueda, y

(c) aquel monto que deja al 50\% de los fondos totales de todas las clases en cuentas que se acogen al Servicio de Búsqueda a través de la presunción legal. Esto asegura que el segmento no afectado por la presunción legal sea siempre sustancial.

En resumen, existen fórmulas capaces de evitar que las AFP ganadoras ahorren en gestión financiera, aunque el Servicio de Búsqueda no tome en cuenta el desempeño financiero ${ }^{49}$.

\section{Incentivos para sustituir comisión propia por las comisiones de} gestores delegados. Cuando un fondo de pensiones invierte en cuotas de otros fondos (por ejemplo, cerca de 25\% está invertido en cuotas de fondos mutuos extranjeros en la actualidad), cuyas administradoras cobran un porcentaje a los fondos administrados, los afiliados pagan una comisión a esas administradoras, que se suma a aquella que pagan a la AFP.

La licitación podría ser ganada por aquella AFP que decida elegir a los fondos mutuos extranjeros que le regalen a ella (a la AFP) el más genero-

${ }^{49} \mathrm{Si}$ se hubiera aplicado la condición (a) por sí sola en diciembre de 2004, el $38,3 \%$ de los fondos en las cuentas de ahorro obligatorio habría pertenecido a afiliados beneficiados por el Servicio de Búsqueda. La presencia de la cláusula (b) sólo puede reducir el umbral efectivo, porque se toma el menor entre (a) y (b), por lo que sólo puede reducir ese $38,3 \%$. 
so servicio de asesoría financiera. Así, esta AFP podría ahorrarse en mayor medida los gastos propios de gestión financiera y algunos gastos comerciales. Estos ahorros podrían resultar cruciales en el contexto de una licitación por precio como la organizada por el Servicio de Búsqueda, pues un menor costo permite ofrecer una comisión menor. Sin embargo, las AFP que sigan esa estrategia no son necesariamente las más baratas para el usuario, porque la menor comisión de la AFP puede estar compensada por comisiones mayores cobradas por aquellos fondos mutuos extranjeros seleccionados por la AFP (que los elige justamente por eso).

Para cancelar este incentivo basta con otorgar a la Comisión Supervisora facultades para incluir en las bases de la licitación un sistema de devoluciones obligatorias, por parte de la AFP ganadora al fondo de pensiones. Por ejemplo, el monto devuelto podría ser aquella parte de las comisiones que apliquen los fondos mutuos donde invierta el fondo de pensiones, que exceda los honorarios medios de gestión que acostumbran pagar inversionistas institucionales de beneficio definido por servicios similares (los planes de pensiones de beneficio definido y las compañías de seguros de vida son los únicos que no están sujetos a los incentivos descritos aquí, pues el patrocinador absorbe el 100\% de las comisiones que cobre algún administrador delegado $)^{50}$.

\section{Incentivos monetarios para mejorar el desempeño financiero. Se-} gún muestran la teoría y la práctica internacional, la comisión que mejor logra estimular una buena gestión financiera es una función creciente del excedente de retorno que obtenga el fondo por sobre aquella obtenida por una cartera de referencia o benchmark, que a su vez es el promedio de los retornos obtenidos por gestores rivales en la misma clase de riesgo ${ }^{51}$. El sistema de banda de rentabilidad relativa no da premio ni castigo alguno al

${ }^{50}$ La tasa marginal de devolución debería variar gradualmente y no abruptamente, en función del tamaño de la diferencia entre las comisiones que el administrador delegado carga al fondo de pensiones, y los honorarios de gestión que pagan los planes de Beneficio Definido.

${ }^{51}$ Por el contrario, un porcentaje aplicado al saldo individual está lejos de esas buenas prácticas. Un motivo es que ese porcentaje daría la parte mayor del premio al mero hecho de administrar el fondo inicial. Se ha dado otra razón a favor de una comisión que sea un porcentaje del saldo: cada AFP daría más importancia a las preferencias de los afiliados de alto saldo, los cuales tienden a estar más informados respecto a la calidad de la gestión financiera que los de bajo saldo. Sin embargo, en esta propuesta los afiliados de alto ingreso (y alto saldo) operan en el segmento de contacto individual, donde pueden hacer valer su información. En todo caso, el estímulo que daría esa comisión sería mucho más débil que aquél creado por el método del benchmark, pues los gestores rivales en la misma clase de riesgo están a su vez mucho mejor informados que los afiliados de alto saldo. 
interior de la banda, y se pierden oportunidades para incentivar una mejor gestión financiera ${ }^{52}$.

Considerando lo anterior, se propone permitir que la Comisión Supervisora fije en las bases de licitación alguna fórmula de comisión por desempeño relativo, con tasas y umbrales prefijados, y deducible del mismo fondo de pensiones. La Comisión Supervisora contaría con la flexibilidad necesaria para explotar esta oportunidad mejor de lo que hizo la ley que estableció una comisión de desempeño para el fondo del seguro de cesantía.

Por ejemplo, la Comisión Supervisora establecería algunos puntos base de premio a la AFP cuando su desempeño (su retorno) supere al benchmark dado por el retorno promedio de los fondos rivales en la misma clase de multifondos; y reduciría ese premio en la medida en que aumente la desviación estándar de la diferencia de retorno con el benchmark ${ }^{53}$.

Este mecanismo de incentivo no tendría costo para los afiliados, porque los postores pronosticarían el monto esperado de la comisión a obtener por esta vía. Para ganar la licitación, reducirían la comisión propuesta en esa misma suma.

\section{La perspectiva del afiliado}

Los resultados del Servicio de Búsqueda desde el punto de vista del afiliado son los siguientes: (i) se termina el neocorporativismo; (ii) se termina con el exceso de vendedores que se ha observado en los episodios de rivalidad de 1981-1982 y 1991-1997, pero no se impide que cumplan su rol educativo; (iii) se reducen las comisiones, porque el Servicio de Búsqueda permitiría traspasar a los cotizantes las actuales utilidades sobrenormales, que son $0,50 \%$ del salario (Cuadro $\mathrm{N}^{\mathrm{o}} 1$ ).

La sección 3.2 estimó que la comisión de las AFP “puras” será 0,21\% del salario. Por otro lado, la sección 6.2 estimó que gracias al aprovechamiento de las economías de escala y ámbito en las operaciones a nivel de todo el sistema, el costo operativo podría llegar a ser el 0,27\% del salario. Sumando una prima de seguro por 1,00\% del salario imponible, la comisión

${ }^{52}$ Los contratos con benchmark y premios han surgido en mercados voluntarios donde no hay banda de rentabilidad relativa.

${ }^{53}$ Como la pensión de los afiliados depende del retorno absoluto y no de la diferencia de retorno (rentabilidad relativa), también correspondería aumentar ese premio en la medida en que disminuya la correlación entre la diferencia de retorno y el nivel absoluto del retorno del benchmark. Sin embargo, esta correlación no puede ser estimada con precisión para un fondo con un alto porcentaje de acciones que cuenta con sólo 24 ó 36 meses de datos de retorno. 
de los "operadores básicos” quedaría en 1,27\% del salario. Sumando todo, resulta una comisión total de 1,48\% del salario. Comparando con la actual comisión de 2,30\% del salario, la diferencia se descompone en una caída de la utilidad sobrenormal por $0,50 \%$ (Cuadro $\mathrm{N}^{\circ} 1$ ) y un ahorro de costos operativos por $0,32 \%$ del salario.

Esta caída permitiría elevar la cotización desde 10,00\% a 10,80\% del salario imponible, dejando constante el salario líquido. Las pensiones alcanzables con una cotización de $10,80 \%$ son $8 \%$ mayores que cuando la cotización es 10,00\%.

Esta rebaja de comisiones aumentaría levemente el empleo cubierto por las AFP y el volumen de cotizaciones para vejez, salud y cesantía, y reduciría en algo el grado de subdeclaración de salarios. Aunque estos efectos sean leves en cantidad, la presencia de otros impuestos y cotizaciones laborales (salud, accidentes, renta) y la alta percepción de impuesto neto que está asociada a la obligatoriedad de la cotización de vejez hacen que la ganancia social tenga una magnitud respetable ${ }^{54}$.

\section{BIBLIOGRAFÍA}

Arrau, P. y S. Valdés: "Para Desconcentrar los Fondos de Pensiones y Aumentar la Competencia en su Administración”. En Estudios Públicos No 85 (verano 2002), pp. 77-100, Santiago, Chile. www.cepchile.cl

Berstein, S. y A. Micco: "Turnover and Regulation: The Chilean Pension Fund Industry”. Banco Central de Chile, Documento de Trabajo Nº 180 (2002), Santiago.

Berstein, S. y J. L. Ruiz: "Sensibilidad de la Demanda con Consumidores Desinformados: El Caso de las AFP en Chile”. Documento de Trabajo No 4 (2005), Superintendencia de AFP, Santiago, Abril. www.safp.cl

Corbo, V. y K. Schmidt-Hebbel: "Efectos Macroeconómicos de la Reforma de Pensiones en Chile”. 2003. Estudio disponible en www.afp-ag.cl

Donoso, A.: "Los Riesgos para la Economía Chilena del Proyecto que Modifica la Estructura de las Comisiones de las AFP”. En Estudios Públicos, 68 (primavera 1997), pp. 11-126. www.cepchile.cl

Goulder, L. y R. Williams: "The Substantial Bias from Ignoring General Equilibrium Effects in Estimating Excess Burden, and a Practical Solution”. En Journal of Political Economy, 4, V. 111 (agosto 2003), pp. 898-927.

Klemperer, P.: "Competition When Consumers Have Switching Costs: An Overview with Applications to Industrial Organization, Macroeconomics and International Trade”. En The Review of Economics Studies, 62, No 4 (1995), pp. 515-539.

${ }^{54}$ Como demuestran Goulder y Williams (2003), el costo social del margen de utilidad (o de un impuesto) es mucho mayor que el tradicional "triángulo" cuando existen otras distorsiones en el mercado laboral, como las cotizaciones de salud y cesantía. 
Larraín, G.: Presentación del Superintendente de AFP llamada "Sistema Previsional Chileno: Más Información para un Mejor Análisis: Encuesta de Historias Laborales y Seguridad Social”. 16 de abril de 2004. Disponible en www.safp.cl

Marinovic, I.: "Estimación de la Demanda por AFP en Chile: 1992-97". Seminario de Título en Microeconomía, Instituto de Economía, Pontificia Universidad Católica de Chile, Santiago, 2000.

Marinovic, I. y S. Valdés: “La Demanda y los Costos de las AFP Chilenas, 1992-2002”. Versión 24 de marzo de 2005. La versión presentada en Seminario Previsional CEP-SAFP, 11 y 12 de noviembre 2004, está en www.safp.cl

Palmer, Edward: “Sweden's New FDC Pension System”. Trabajo presentado en Seminario Previsional CEP-SAFP, 11-12 de noviembre de 2004, Santiago. www.safp.cl

Salop, S. y J. Stiglitz: "Bargains and Ripoffs: A Model of Monopolistically Competitive Price Dispersion”. En Review of Economic Studies, 44 (1977), pp. 493-510.

Stiglitz, J.: "Imperfect Information in the Product Market". En R. Schmalensee y R. Willig (eds.), Handbook of Industrial Organization, Vol. I. North Holland: Elsevier Science Publishers, 1989, pp. 769-847.

Sutton, J.: Sunk Costs and Market Structure. Cambridge University Press, 1991.

Valdés, S.: "Vendedores de AFP: ¿Producto del Mercado o de Regulaciones Ineficientes?”. Documento de Trabajo $\mathrm{N}^{\circ} 178$, Instituto de Economía, Pontificia Universidad Católica de Chile, marzo 1995. http://volcan.facea.puc.cl/economia

Valdés, S.: "Libertad de Precios para las AFPs: Aún Insuficiente". En Estudios Públicos $\mathrm{N}^{\circ} 68$ (primavera 1997), Centro de Estudios Públicos, pp. 127-148.

Valdés, S.: "Pricing and Marketing Rules with Brand Loyalty". Documento de Trabajo $\mathrm{N}^{\circ}$ 210, Instituto de Economía, Universidad Católica, marzo 2002. http:// volcan.facea.puc.cl/economia

Valdés, S. e I. Marinovic: "Pension Fund Managers in Reformed Systems”. En J. Meléndez y Eduardo Rodríguez-Oreggia (editores), The Americas Social Security Report 2003: Evaluation of the Reforms. Mexico City, Mexico: Interamerican Conference on Social Security (CISS), 2003. www.ciss.org.mx

Valdés, S. e I. Marinovic: “Contabilidad Regulatoria: Las AFP Chilenas, 1993-2003”. Documento de Trabajo, Instituto de Economía, Pontificia Universidad Católica de Chile, 2004. http://volcan.facea.puc.cl/economia 